\title{
Recent therapeutic applications of the theranostic principle with dendrimers in oncology
}

\author{
Serge Mignani ${ }^{1,2^{*}}$, Joao Rodrigues ${ }^{2,3^{*}}$, Helena Tomas ${ }^{2}$, Anne-Marie Caminade ${ }^{4,5}$, Régis Laurent ${ }^{4,5}$, \\ Xiangyang $\mathrm{Shi}^{6^{*}}$ and Jean-Pierre Majoral ${ }^{4,5^{*}}$
}

\begin{abstract}
At the intersection between treatment and diagnosis, nanoparticles technologies are strongly impacting the development of both therapeutic and diagnostic agents. Consequently, the development of novel modalities for concomitant noninvasive therapy and diagnostics known as theranostics as a single platform has gained significant interests. These multifunctional theranostic platforms include carbon-based nanomaterials (e.g., carbon nanotubes), drug conjugates, aliphatic polymers, micelles, vesicles, core-shell nanoparticles, microbubbles and dendrimers bearing different contrast agents and drugs, such as cytotoxic compounds in the oncology domain. Dendrimers emerged as a new class of highly tunable hyperbranched polymers, and have been developed as useful theranostic platforms. Magnetic resonance imaging, gamma scintigraphy, computed tomography and optical imaging are the main techniques developed with dendrimers in the theranostic domain in oncology. Different imaging agents have been used such as $\mathrm{Gd}(\mathrm{III}),{ }^{19} \mathrm{~F}, \mathrm{Fe}_{2} \mathrm{O}_{3}$ (MRI), ${ }^{76} \mathrm{Br}$ (PET), ${ }^{111} \mathrm{In},{ }^{88} \mathrm{Y},{ }^{153} \mathrm{Gd},{ }^{188} \mathrm{Re},{ }^{131} \mathrm{I}$ (SPECT), ${ }^{177} \mathrm{Lu}$, gold (CT) and boronated groups, siliconnaphthalocyanines, dialkylcarbocyanines and QDs (optical imaging dyes).
\end{abstract}

Keywords: theranostic platforms, dendrimers, magnetic resonance imaging, gamma scintigraphy imaging, computed tomography imaging, optical imaging

\section{INTRODUCTION}

For decades, the development of medical nanotechnology, now a cornerstone of modern medicine, has allowed innovative applications [1]. In oncology, Doxil ${ }^{\mathrm{TM}}$ and Abraxame $^{\mathrm{TM}}$ are two representative nanoparticle formulations, which contain doxorubicin and taxol, respectively, and are used to treat cancer. In general, the use of nanoparticles results in a decrease in toxicity and an increase in efficacy compared with the drug alone $[2,3]$. In medicine, nanoparticles have been described using several different types, including liposomes, albumin-based particles, biodegradable polymer-drug composites, PEGylated proteins, polymeric micelles, polymer-drug conjugate-based particles, carbon nanomaterials, inorganic particles, dendrons, and dendrimers [4]. Developed in the last 30 years, dendrimers represent an important versatile and well-defined nanosized architecture. Dendrimers have played a key role in drug delivery with several advantages: 1 ) reducing the toxicity of the drug alone; 2) extending the route of administration; 3) improving the disease outcomes of drugs; and 4) improving the pharmacokinetic/pharmacodynamic (PK/PD) profile of drugs. Drug delivery systems and dendrimers as drugs alone are the two main therapeutic applications of dendrimers. Dendrimers exhibit a number of important attributes in nanomedicine, including homogeneity,

\footnotetext{
${ }^{1}$ Université Paris Descartes, PRES Sorbonne Paris Cité, CNRS UMR 860, Laboratoire de Chimie et de Biochimie Pharmacologiques et Toxicologique, 45, rue des Saints Peres, 75006 Paris, France

${ }^{2}$ CQM - Centro de Quimica da Madeira, MMRG, Universidade da Madeira, Campus da Penteada, 9020-105, Funchal, Portugal

${ }^{3}$ School of Materials Science and Engineering/Center for Nano Energy Materials, Northwestern Polytechnical University, Xi'an 710072, China

${ }^{4}$ Laboratoire de Chimie de Coordination du CNRS, 205 Route de Narbonne, BP 44099, 31077 Toulouse Cedex 4, France

${ }^{5}$ Université de Toulouse, UPS, INPT, 31077 Toulouse Cedex, France

${ }^{6}$ State Key Laboratory for Modification of Chemical Fibers and Polymer Materials, College of Chemistry, Chemical Engineering and Biotechnology, Donghua University, Shanghai 201620, China

* Corresponding authors (emails: serge.mignani@parisdescartes.fr (Mignani S); joaor@uma.pt (Rodrigues J); xshi@dhu.edu.cn (Shi X); majoral@lcctoulouse.fr (Majoral JP))
} 
monodispersity derivatisability, reproducibility, tailored multivalency, higher permeation and circulation, and strong spatial distribution of multiple functions on their surface, which are important for the delivery of active pharmaceutical agents, such as small and macrocyclic drugs, small interfering RNAs, and antibodies, for several pharmaceutical applications, including cancer, inflammation, and infection (e.g., HIV).

Several types of dendrimers have been highlighted, and can be classified based on their chemical moieties and the type of structural linkages: glycodendrimers, peptide dendrimers, Janus dendrimers, metallodendrimers, and phosphorus dendrimers [5-7]. Dendrimers can be compared with proteins based on their size and physicochemical properties. Biodegradability and biocompatibility are important for the bioapplications of dendrimers, especially blood circulation and possible side effects, respectively, in vivo.

In 2012, Starpharma initiated two pivotal Phase III trials for the treatment of bacterial vaginosis with Viva$\mathrm{Gel}^{\circledR}$ (SPL7013 Gel) [8,9]. This active polyanionic G4-poly (L-lysine)-type dendrimer has 32 naphthalene disulphonate groups on the surface, and showed potent topical vaginal microbicidal activity. Starpharma has now received Food and Drug Administration Phase III approval. Starpharma/AstraZeneca has recently advanced from Phase I to Phase II with a poly(lysine)-dendrimer based nanocarrier encapsulating docetaxel $\left(\mathrm{DEP}^{\circledR}\right.$ docetaxel), which shows superior anticancer activity against several solid cancer types, including breast, prostate, lung, and ovarian tumors.

Theranostics is an emerging noninvasive concept that enables the simultaneous use of diagnostic tests and targeted therapy. This strategy is based on multifunctional nanoparticles as one integrated system (a single platform), and simultaneous monitoring of the therapeutic response. Over the past few decades, theranostic nanoparticles (TNPs) that simultaneously transmit diagnostic information and monitor the therapy process in situ have been developed [10,11]. The objective of diagnostic agents is to enhance the visibility of specific tissues, providing a quick and high fidelity snapshot of the living system with a rapid and slow clearing strategy, whereas therapeutic agents generally play their specific treatment role with the long-circulating profile of nanoparticles.

The typical imaging modalities are: 1) optical imaging using photons from bioluminescent or fluorescent probes; 2) magnetic resonance imaging (MRI) using gadolinium (Gd) [12], and manganese oxide based on the precession of water hydrogen nuclei within an applied magnetic field; 3) radionuclide-based imaging using the electromagnetic spectrum $\gamma$-ray emissions (positron emission tomography (PET) and single photon computed tomography (SPECT)); 4) computed tomography (CT) measuring the absorption of X-rays through tissues, with gold nanoparticles as the most popular CT contrast agent; and 5) ultrasound (US), high frequency sound waves $>20 \mathrm{kHz}$. Table 1 shows the main imaging modalities as well as the advantages and disadvantages of the molecular imaging strategies for theranostic applications.

The main effective TNPs are 1) drug conjugates (e.g., $\mathrm{N}$-(2-hydroxypropyl)methacrylamide (HPMA) and complexes; 2) vesicles such as liposomes and polymer vesicles; 3) micelles (e.g., polyethylene glycol-polylactic acid (PEGPLA); 4) core-shell structured TNPs including quantum dots (QDs), metals, and metal oxides; 5) microbubbles (e.g., PEG-poly-L-lactide/perfluoropentane (PEG-PLLA/ PFP); 6) carbon nanotubes; and 7) polymeric materials such as aliphatic polyesters [13], dendritic polymers [11], and dendrimers (e.g., polyamidoamine dendrimer-PEG (PAMAM-PEG)) [14].

TNPs, except dendrimers, are primarily developed for use in cancer treatment (Table 2). Indeed, conventional chemotherapy shows a low therapeutic window and poor prognosis of patients diagnosed with metastatic cancers. Consequently, the development of newer strategies to simultaneously detect cancer lesions at an early stage and to precisely deliver anticancer drugs to tumor sites remains an important area of research.

Dendrimers are hyperbranched nanostructures with controlled functionality and are vehicles that can be efficiently tailored for the spatial distribution of various functionalities on their surface. These versatile functions, which allow stimuli-response ability and the ability to self-assembly, make dendrimers excellent candidates for theranostic applications [5]. Importantly, the co-delivery of diagnostic and therapeutic agents represents a valuable real-time validation of therapy. Fig. 1 shows a schematic illustration of a theranostic dendrimer for simultaneous diagnosis, therapy, and therapeutic monitoring.

Cancer theranostics has been developed to fight this terrible disease by improving treatment efficiency and by precisely diagnosing specific cancer types and monitoring therapy. Several imaging methods, such as US, CT, PET, and MRI, have been developed for this purpose. However, none of these imaging techniques represent ivory towers. Several limitations have been noted, including poor resolution, inherent radiation damage, and high equipment costs. In comparison with these methods, conventional fluorescence imaging techniques exhibit advantages: high 
Table 1 Imaging modality, type of imaging agents and their respective advantages and disadvantages

\begin{tabular}{|c|c|c|c|}
\hline Imaging modality & Type of imaging agent & Advantages & Disadvantages \\
\hline Optical imaging dye & Fluorescent dyes, photoproteins, quantum dots & $\begin{array}{l}\text { High sensibility } \\
\text { No radiation } \\
\text { Multi-channel imaging }\end{array}$ & $\begin{array}{l}\text { Not for clinical imaging } \\
\text { Low resolution } \\
\text { Limited tissue penetration } \\
(<1 \mathrm{~cm})\end{array}$ \\
\hline Computed tomography (CT) & Heavy elements, e.g. iodine, gold & $\begin{array}{l}\text { High spatial resolution } \\
\text { Low radiation exposure } \\
\text { Tissue differentiation } \\
\text { No depth limit } \\
\text { Relatively low cost }\end{array}$ & $\begin{array}{l}\text { Radiation } \\
\text { Nontissue-specificity } \\
\text { Need contrast agent for } \\
\text { tissue differentiation } \\
\text { Mainly used for lung and } \\
\text { bone }\end{array}$ \\
\hline $\begin{array}{l}\text { Magnetic resonance imaging } \\
\text { (MRI) }\end{array}$ & $\begin{array}{l}\text { Para- or supramagnetic metals (e.g., } \mathrm{Gd}(\mathrm{III}) \text {, } \\
\text { manganese oxide, } \mathrm{Fe}_{2} \mathrm{O}_{3} \text {, or } \mathrm{Fe}_{3} \mathrm{O}_{4} \text { ) } \\
{ }^{19} \text { Fluorine labeled compounds }\end{array}$ & $\begin{array}{l}\text { High resolution } \\
\text { No ionizing radiation } \\
\text { Physiological and anatomical images } \\
\text { No depth limit } \\
\text { Quantitative results }\end{array}$ & $\begin{array}{l}\text { Limited to patients with- } \\
\text { out metallic devices (e.g., } \\
\text { pacemakers) } \\
\text { High cost }\end{array}$ \\
\hline Gamma scintigraphy (PET) & $\begin{array}{l}\text { Radionuclides } \\
\text { (e.g., }{ }^{18} \mathrm{~F},{ }^{11} \mathrm{C},{ }^{64} \mathrm{Cu},{ }^{15} \mathrm{O},{ }^{76} \mathrm{Br} \text { ), }\end{array}$ & $\begin{array}{l}\text { Image biochemical process } \\
\text { High sensitivity } \\
\text { No depth limit }\end{array}$ & \multirow{2}{*}{$\begin{array}{l}\text { Radiation } \\
\text { Low resolution } \\
\text { Limited imaging depth } \\
(\mathrm{cm})\end{array}$} \\
\hline Gamma scintigraphy (SPECT) & ${ }^{111}$ In chelates, ${ }^{99} \mathrm{mTc}$ & $\begin{array}{l}\text { Quantitative results } \\
\text { Low cost }\end{array}$ & \\
\hline Ultrasound & Gas-filled microbubbles & $\begin{array}{l}\text { High resolution } \\
\text { Non invasive } \\
\text { Simple procedure to operate } \\
\text { No radiation exposure } \\
\text { Low cost }\end{array}$ & Low resolution \\
\hline
\end{tabular}

Table 2 Selected examples of TNPs in oncology (except dendrimers)

\begin{tabular}{|c|c|c|c|c|}
\hline TNPs type & Material involved & Anticancer drugs & Contrast agents & Targeting moieties \\
\hline Carbon nanotubes & Carbon & Cisplatin & Quantum dots & $\mathrm{EGF}^{\mathrm{i}}[15]$ \\
\hline Drug conjugates & HPMA $^{\mathrm{a}}$ & & DY-615 & $\operatorname{RGD}^{j}[16]$ \\
\hline Aliphatic polyesters & $\mathrm{PLGA}^{\mathrm{b}}+$ poly(allylamine $) / \mathrm{PEG}$ & Docetaxel & SPIO $^{f}$ & $\mathrm{SCA}^{\mathrm{b}}$ antibody [17] \\
\hline Micelles & PEG-PLA ${ }^{\mathrm{c}}$ & Doxorubicin & SPIO $^{f}$ & $\mathrm{RGD}^{\mathrm{j}}[18]$ \\
\hline Vesicles & $\mathrm{PBGBH}^{\mathrm{d}}$ & Docetaxel & $\mathrm{Tc}-99^{\mathrm{m}}$ & Passive diffusion [19] \\
\hline Core-shell nanoparticles & $\mathrm{PAA}^{\mathrm{e}} / \mathrm{SPIO}^{\mathrm{f}}$ & Paclitaxel & SPIOf $/$ Dil $^{\text {h }}$ & Folic acid [20] \\
\hline Microbubbles & PEG-PLA $/$ PFP $^{g}$ & Doxorubicin & $\mathrm{PFP}^{\mathrm{g}}$ & Passive diffusion [21] \\
\hline
\end{tabular}

a: $N$-(2-hydroxypropyl)methacrylamide, b: poly(lactic-co-glycolic acid), c: polylactic acid, d: poly(g-benzyl-L-glutamate)-block-hyaluronan; e: polyacrylic acid; f: superparamagnetic iron-oxide; g: pentafluorophenyl ester; h: 1,1-dioctadecyl-3,3,3,3-tetramethylindocarbocyanine perchlorate; i: epidermal growth factor; j: Arg-Gly-Asp peptide

spatial resolution, strong biocompatibility, and low cost. However, due to the aggregation-caused quenching effect and background noise in dilute solutions, applications of these techniques in theranostics have been strongly limited. Aggregation-induced emission probes show excellent photo-stability and a reduced self-quenching effect and have been incorporated into theranostic platforms. Up until now, no ideal TNPs have been developed and theranostics remains an important area of research in nanomedicine to treat important chronic diseases such as cancer.
In this concise review, we briefly summarize and describe the recent progress in the development of dendrimers for theranostic applications in oncology. In particular, we analyze their specific properties in relation with theranostic-related applications.

\section{DENDRIMERS FOR THERANOSTIC APPLICATIONS}

Based on the precise regulation of the polymerization and synthesis of polymeric dendrimers, the molecular weight and chemical composition (polydispersity) of the final 


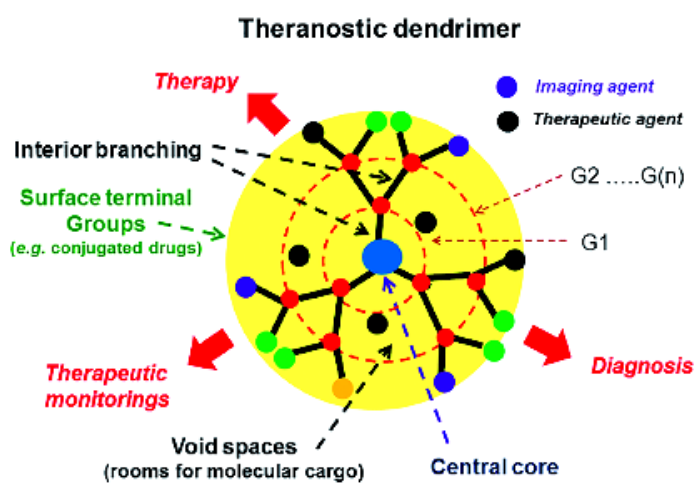

Figure 1 Schematic description of theranostic dendrimer strategy.

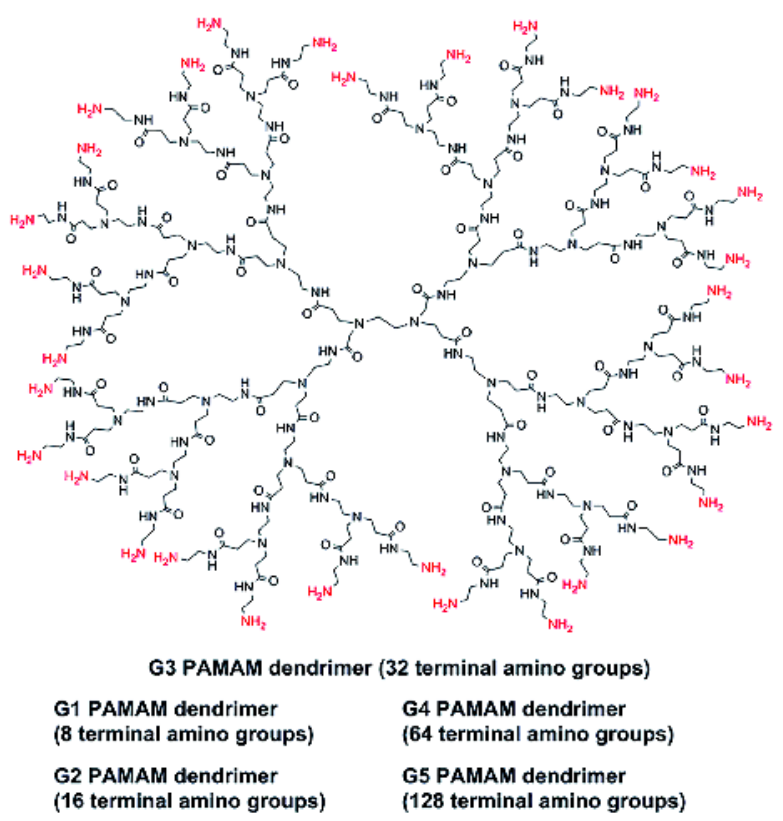

Figure 2 2D chemical structure of G1-G5 PAMAM dendrimers.

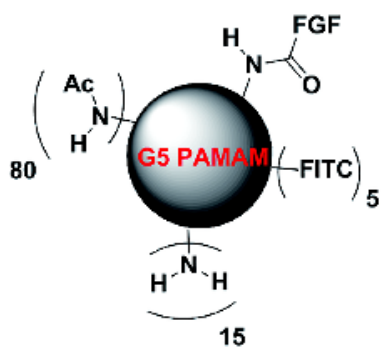

Figure 3 Schematic chemical structure of G5 FGF-dendrimer conjugate.

nanoparticles can be monitored, and thus, dendrimers are ideal platforms for TNPs.

This review has been divided based on imaging mod-

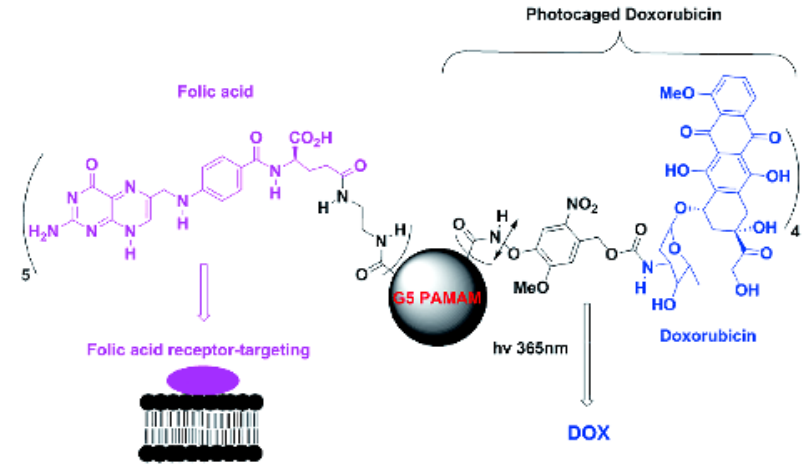

Figure 4 Schematic chemical structure of G5 DOX-FA-dendrimer conjugate.

alities: MRI, gamma scintigraphy (PET), gamma scintigraphy (SPECT), CT, and optical imaging. Up until now, the main dendrimer used for theranostic applications in oncology has been the polyamidoamide (PAMAM) dendrimers (Starburst ${ }^{\mathrm{TM}}$ dendrimers). Fig. 2 shows the twodimensional chemical structure of the G3 PAMAM dendrimer and the number of amino-terminal groups of G1, G2, G4, and G5 PAMAM dendrimers. The molecular weight $\left(\mathrm{g} \mathrm{mol}^{-1}\right)$ and hydrodynamic radius $(\mathrm{nm})$ are 609 , $1.5 ; 1,522,2.2 ; 3,348,2.9 ; 7,001,3.6 ; 14,307,4.5$ and 28,918, 5.4 for PAMAM generation $0,1,2,3,4$ and 5, respectively.

Selected examples of the design of targeted dendrimers for theranostic applications in oncology

Thomas et al. [22] described the preparation of G5 PAMAM dendrimers conjugated to fluorescein isothiocyanate for imaging and recombinant fibroblast growth factor-1 (FGFR), which is overexpressed in a wide variety of tumors, for tumor targeting purposes (Fig. 3). Confocal microscopy and flow cytometry showed the specific binding and the internalization of the G5 FGFRdendrimer conjugate. The binding of the conjugated nanoparticles showed modest binding in the breast cancer cell line MCF7, which is FGFR-negative in unstimulated MCF7 cells, and significant specific activity against the PC3 prostate cancer and MCR endothelial cell lines.

The same authors reported the synthesis and in vitro evaluation of a G5 PAMAM-folate receptor (FR)-targeted nanoconjugate that releases the anticancer drug doxorubicin (DOX) via a photochemical mechanism (Fig. 4) [23]. Doxorubicin is loaded onto the surface of the dendrimer through the UV photocleavable ortho-nitrobenzyl group linker at $365 \mathrm{~nm}$.

Another study described by Singh et al. [24] highlighted the site-specific enhanced image contrast and drug loca- 

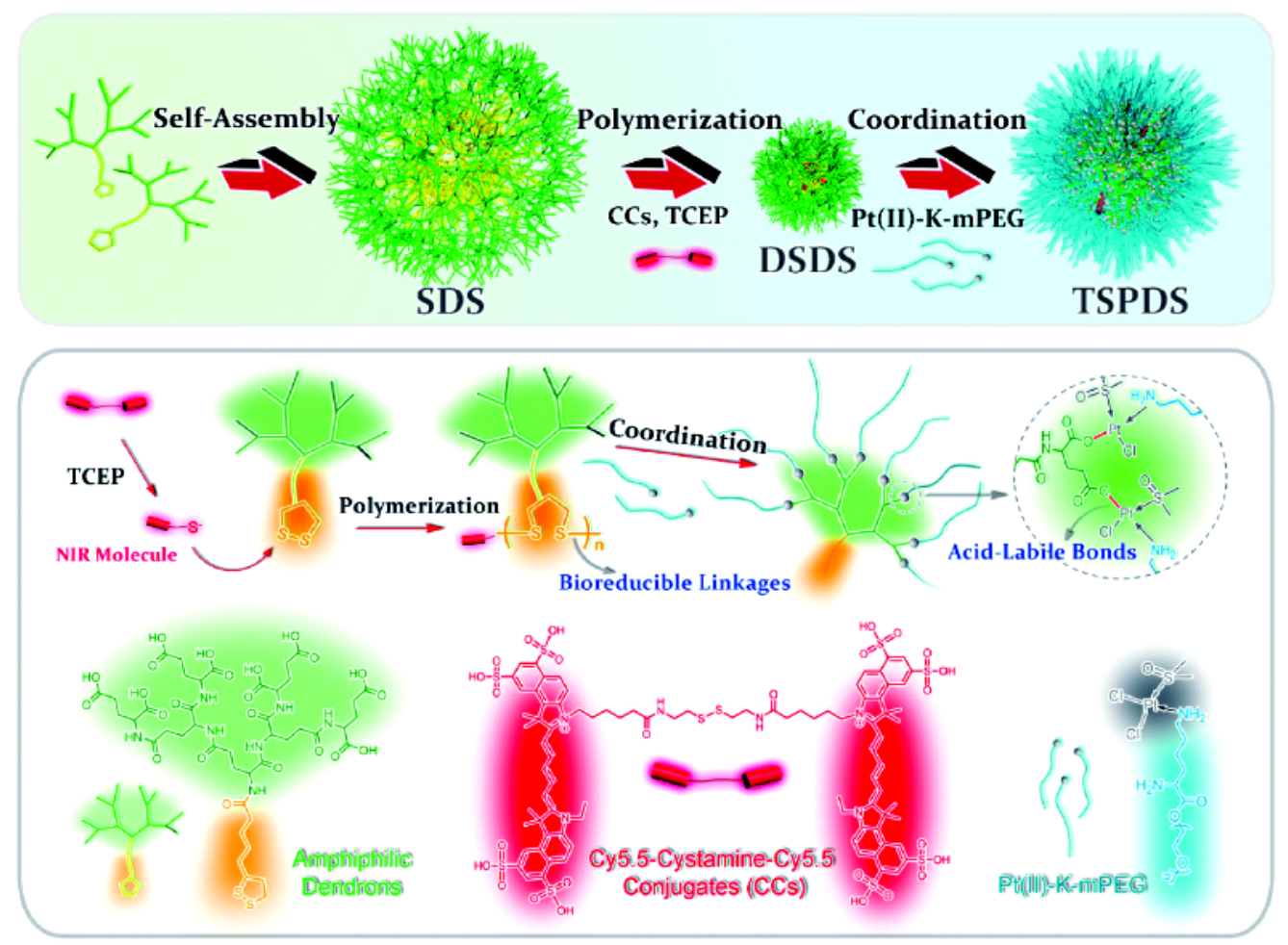

Figure 5 Schematic illustrations of the synthesis of TSPDS based on self-assembly, polymerization and coordination steps. Reprinted with permission from Ref. [26], Copyright 2016, Ivyspring International Publisher.

lization with the G4 PAMAM dendrimer conjugated with folic acid (FA) as a targeting agent. Two linker types have been prepared to link FA with the amino groups on the dendrimer surface: direct FA conjugate and FA-PEG [poly(ethylene glycol)]-N-hydroxysuccinimide (NHS) conjugate. These dendritic conjugates were evaluated for their anti-cancer drug delivery and tumor growth efficiency using loaded 5-fluorouracil ( $31 \%)$ against cervical $\mathrm{KB}$ tumor cells in mice. Interestingly, the folate-PEG -dendrimer conjugate was safe and effective in tumor targeting compared with a non-PEGylated formulation.

Another example of the development of FA-PEG-G3.5 PAMAM conjugates onto quantum dots (QDs) in HeLa tumor cells has been described by Zhao et al. [25]. Significant cellular uptake was observed based on in vivo imaging experiments.

Recently, Li and coworkers [26] described the preparation and development of PEGylated supramolecular nanoplatforms based on lipoic acid-functionalized amphiphilic dendrons for efficient platinum(II)-based drug delivery and near-infrared (NIR) absorption tracking using Cy5.5 as NIR fluorescence probes named TSPDS (Fig. 5). Interestingly, the rapid disintegration of this supramolecular dendritic system occurred by a $\mathrm{pH} /$ redox dual-responsive process based on the specific tumor intracellular environment: low $\mathrm{pH}$ value and high glutathione concentration. The redox-cleavable disulfide linkages and the release of platinum(II) drug by the acidlabile bonds around the metal occurred in the nuclei exerting antitumor activity, which was comparable to cisplatin in the A549 lung solid tumor cell line. In vivo, this supramolecular platform showed efficient therapeutic efficacy against nude mice with A549 xenografts following intravenous injection. In vitro and in vivo NIR fluorescence imaging, also in nude mice with A549 tumor xenografts, showed the intracellular platinum delivery of the nanodevice. The pharmacokinetic profile showed that the maximum plasma concentration $\left(C_{\max }\right)$ of $\mathrm{Pt}(\mathrm{II})$ from the PEGylated nanodevice was approximately eight-fold higher than cisplatin alone. In addition, higher accumulation in tumor tissue compared with cisplatin has been noted, minimizing nephrotoxicity and enhancing the antitumor effects. The area under the curve (AUC), the half-life $\left(t_{1 / 2}\right)$, and the blood clearance profiles of the nanodevice were improved compared with cisplatin, with a 22-fold increase, three-fold increase, and 20-fold decrease, respectively. Importantly, based on cellular morphological analysis, strongly reduced renal toxicity (cell 

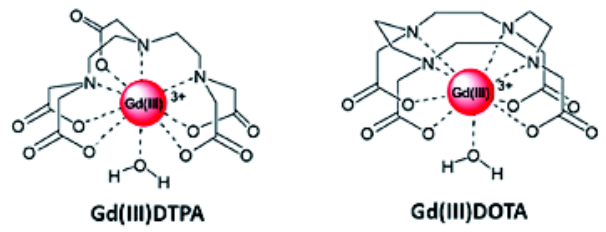

Figure 6 Schematic chemical structure of Gd(III) complexed with DTPA and DOTA.

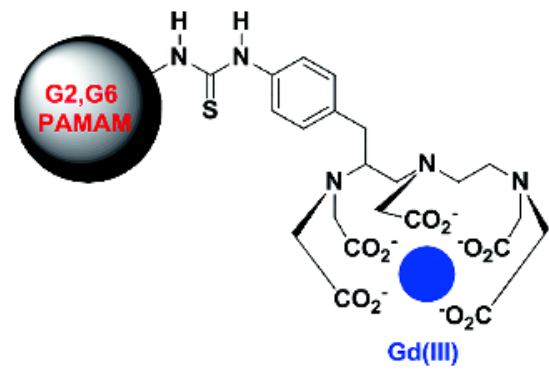

Figure 7 Schematic chemical structure of G2, G6 PAMAM-DTPA dendrimers.

deformation in renal tissue) of platinum-based drugs has been observed compared with cisplatin. No lesions as well as no abnormalities in other major organs, such as the heart, liver, spleen, and lung, were observed in mice.

These non-exhaustive examples (vide supra) highlight the potential role of dendrimers in the theranostic field.

\section{Magnetic resonance imaging}

An interesting analysis of dendrimers as versatile MRI agents has been recently published by McMahon et al. [14]. Paramagnetic Gd(III) [27] and Mn(II) dendrimers [28], as well as the use of superparamagnetic iron-oxide nanoparticles, which allow the formation of superparamagnetic dendrimers (also named magnetodendrimers), have been prepared. Thus, the stabilization of maghemite nanoparticles by G4.5 PAMAM dendrimers allows the use of these nanoparticles in MRI cell tracking studies [29,30]. Additional dendrimer-MRI contrast agents include chemical exchange saturation transfer (CEST), diamagnetic CEST, paramagnetic CEST $[31,32]$, and fluorinated dendrimers [33].

Gadolinium (Gd(III)) has seven unpaired electrons, and this paramagnetic nanodevice displays the highest relaxivity related to the nuclear magnetic resonance frequency, whereas manganese $(\mathrm{Mn}(\mathrm{II}))$ shows anomalous relaxation behavior, and at higher fields, exhibits relaxation that is higher than gadolinium [14].

MRI contrast agents currently approved for clinical applications are mostly low-molecular weight Gd(III) chelates, such as Gd-diethylenetriaminepentaacetic acid (DTPA) and Gd-tetraazacyclododecane-1,4,7,10-tetraacetic acid (DOTA), but these imaging agents rapidly extravasate from blood circulation and are eliminated via renal filtration (Fig. 6). Consequently, a transient time window for contrast-enhanced MRI examinations and limited efficacy in improving MRI quality were observed. Consequently, macromolecular Gd(III) complexes show prolonged blood circulation and preferential accumulation in solid tumors due to the hyperpermeability of tumor vasculature [34].

The addition of Gd(III) to create dendrimer-based MRI contrast agents has been described by several groups. The first study to validate the feasibility of using dendrimers chelated with metals ions as MRI contrast agents was published by Wiener et al. [27] and showed the applicability of G2 and G6 PAMAM dendrimers as MRI contrast agents [28]. The surface of PAMAM dendrimers was functionalized with DTPA to complex Gd(III) as an imaging agent. In total, 11 and 170 chelate groups were grafted on the surface of G2 and G6, respectively (Fig. 7). These Gd(III)-macromolecules enhanced conventional MRI in mice. The generation 6 dendrimer displayed a prolonged enhancement compared with G2 and Gd(III)DTPA. The enhancement half-lives were 200, 40, and 24 min for G6, G2, and Gd(III)-DTPA, respectively. In addition, the G6 dendrimer overcame the saturation effects associated with the three-dimensional time of flight MRI angiography associated with a long longitudinal relaxation time of the blood. Other biodegradable dendrimer-based MRI contrast agents (Gd(III)-DTPA) are as follows: 1) PEG-conjugated ester-amide dendrimer [35]; 2) G0-3 polyester (PE) dendrimers [36]; 3) G2 FA-PEGconjugated PE dendrimer [37]; and 4) G1-G4 PEG-conjugated PE dendrimer [38].

The G4 PAMAM dendrimer has been synthesized and developed for use as a target-specific MRI contrast agent by Konda et al. [39] with Gd(III)-DTPA chelates and FA units to target upregulated FRs in more than $80 \%$ of ovarian tumors. In vitro, mouse erythroleukemia cells expressing FRs bind the radiolabeled folate-dendrimer chelate, resulting in a greater than $2700 \%$ increase in binding compared with untreated cells. In vivo, this macrocycle showed significant contrast enhancement (33\%) in ovarian tumor xenografts in mice compared with a non-specific agent without FA. These studies suggest that dendrimeric MRI agents with high molecular relaxivities $\left(1,646 \mathrm{mmol}^{-1} \mathrm{~L} \mathrm{~s}^{-1}\right)$ can be used to specifically target FRs on tumor cells and ovarian tumors. 

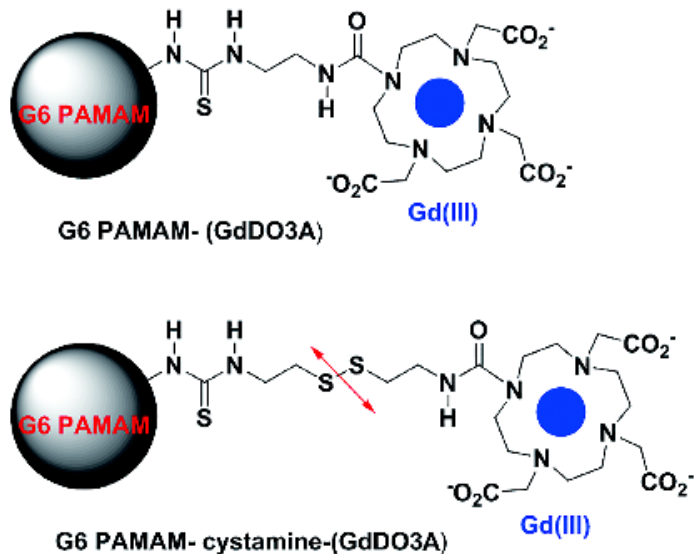

Figure 8 Schematic chemical structure of G6 PAMAM-(GdDO3A) and G6 PAMAM-cystamine-(GdDO3A).

It is known that macromolecular Gd(III) chelates are efficient as MRI contrast agents for blood pool and tumor imaging [40]. The main drawback of this system is their limitation in clinical development, such as safety concerns related to slow excretion and long-term gadolinium uptake in tissues. To solve these issues, $\mathrm{Xu}$ et al. [34] prepared G6 PAMAM conjugated with Gd(III) DO3A chelate [G6 PAMAM-(Gd-DO3A)] and cleavable disulfide spacer [G6-PAMAM-cystamine-(Gd-DO3A)] dendrimers as biodegradable macromolecular MRI contrast agents (Fig. 8). This G6 PAMAM dendrimer showed rapid blood clearance and lower liver uptake in nude mice compared with a non-degradable G6 PAMAM-Gd(III) dendrimer without cleavable cystamine linker following intravenous injection. Dynamic MRI showed that the Gd (III) chelate was excreted via renal filtration and accumulated in the urinary bladder. The $\mathrm{T} 1$ and $\mathrm{T} 2$ relaxivities of the G6-PAMAM-Gd(III)-cystamine dendrimer were 11.6 and $13.3 \mathrm{mmol}^{-1} \mathrm{~L} \mathrm{~s}^{-1}$, respectively. The G6-PAMAM-Gd(III)-cystamine dendrimer was effective for contrast-enhanced blood pool imaging for approximately $5 \mathrm{~min}$, and tumor imaging in female nude mice bearing MDA-MB-231 human breast carcinoma xenografts. However, the G6-PAMAM-Gd(III)-cystamine dendrimer displayed high toxicity in mice, likely due to the hemotoxicity related to the inherent toxicity of the PAMAM dendrimer structure.

Several other examples in which Gd(III)-DOTA was covalently grafted onto the dendrimer backbone for molecular imaging purposes, such as MRI angiography and tumor angiogenesis imaging, include: poly-L-lysine octasilsesquioxane dendrimers developed by Kaneshiro et al. [41] and PEG-backbone core dendrimeric nanoparticles bearing Gd-DOTA chelate clusters as dynamic MRI contrast agents developed by Cyran et al. [42]. As shown in Fig. 9, Cyran et al. [42] prepared three different contrast agents based on PEG-core and (Gd-DOTA)-conjugated units: PEG12000-Gen3-(Gd-DOTA), PEG12000-Gen4(Gd-DOTA), and PEG20000-Gen4-(Gd-DOTA). These polymeric MRI contrast agents displayed T1 relaxivity per Gd ion of 9.0, 9.9 and $9.8 \mathrm{mmol}^{-1} \mathrm{~L} \mathrm{~s}^{-1}$, respectively, and blood half-life of 25,49 and $72 \mathrm{~min}$, respectively. These macromolecular systems have been used in quantitative assays of endothelial leakiness and tissue vascular tissue density to differentiate cancer and normal cells in a model of human breast cancer (MDA-MB-435) in mice. PEG20000-Gen4-(Gd-DOTA) showed high breast tumor penetration and low trans-endothelial residence in normal soft tissue microvessels. PEG20000-Gen4-(GdDOTA) displayed good differentiation of cancers from normal muscle. PEG12000-Gen4-(Gd-DOTA) and PEG12000-Gen3-(Gd-DOTA) both showed penetration in a breast tumor and normal muscle.

Recently, the first in vivo MRI study on the theranostic potential of dendrimersomes (amphiphilic Janus-dendrimers as a relevant alternative to liposomes), which are able to self-assemble into nanosized vesicles, was de-

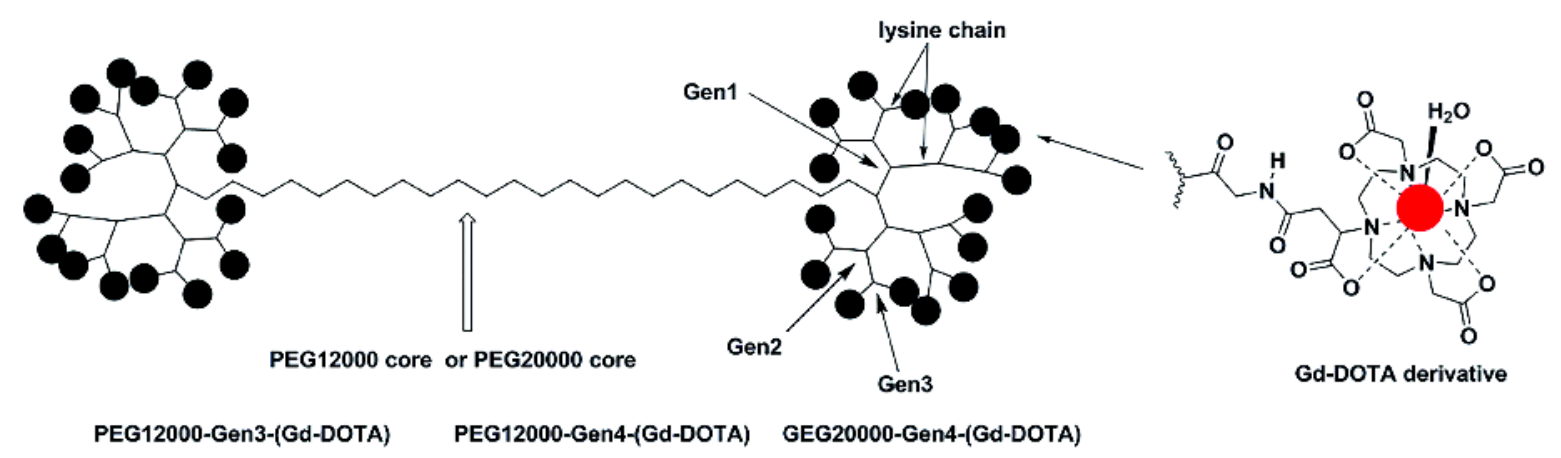

Figure 9 Schematic chemical structure of polyethylene glycol (PEG)-core-(Gd-DOTA) dendrimers. 


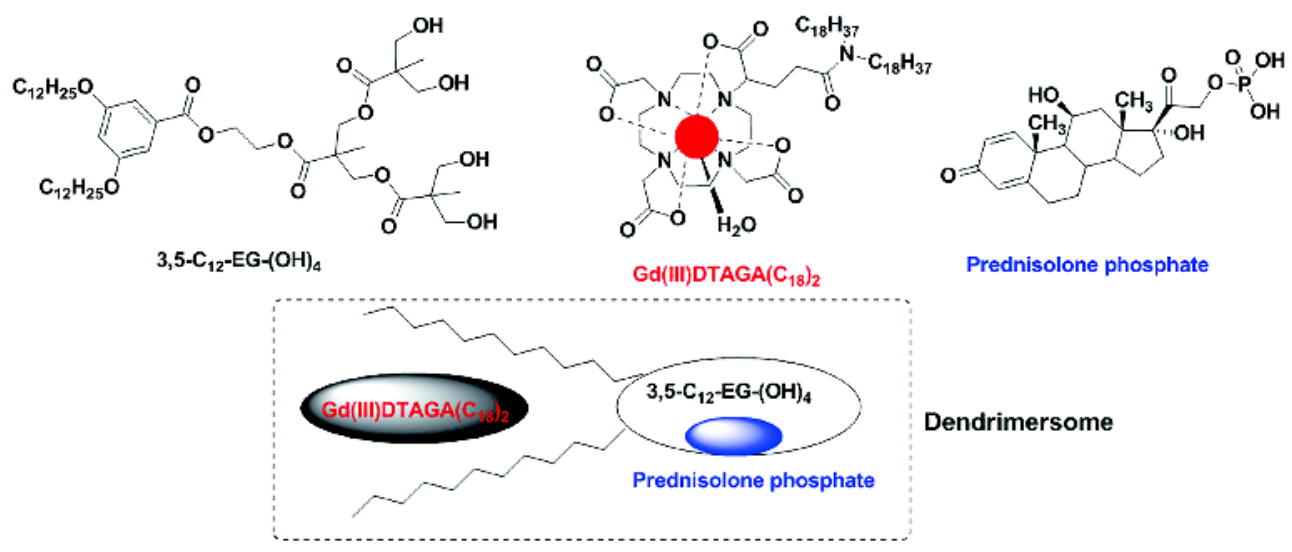

Figure 10 Chemical structure of dendrimersome based on 3,5- $\mathrm{C}_{12}-\mathrm{EG}-(\mathrm{OH})_{4}, \mathrm{Gd}(\mathrm{III}) \mathrm{DTAGA}\left(\mathrm{C}_{18}\right)_{2}$ and prednisolone phosphate.

scribed by Filippi et al. [43]. As shown in Fig. 10, this Janus construction is based on the $3,5-\mathrm{C}_{12}$-EG- $(\mathrm{OH})_{4}$ dendrimer co-loaded with the glucocorticoid anticancer agent prednisolone phosphate, which is encapsulated in the inner core of the dendrimersome, and the amphiphilic MRI agent $\mathrm{Gd}(\mathrm{III}) \mathrm{DOTAGA}\left(\mathrm{C}_{18}\right)_{2}$, which is incorporated in the dendrimersome bilayer. In cell viability assays, this dendrimersome displayed no toxicity against murine fibroblast cell line (NIH/3T3) indicating no toxicity associated with the presence of the vehicle. Strong cytotoxicity was observed against HUVEC cell lines and moderate against melanoma B16-F10 tumor cells after incubation times of 6 and $24 \mathrm{~h}$. This nanovesicle showed high longitudinal relaxivity and consistent contrast enhancement in a xenograft B16F10 melanoma tumor in mice. Intratumoral distribution appeared inhomogeneous, likely due to local differences in the vascularization. Dendrimersome biodistribution studies showed a high concentration in the liver, spleen, and tumor compared with other organs such as the kidney, lung, muscle and heart.

Criscione et al. [44] developed noninvasive perfluorinated G3 and G6 PAMAM-dendrimers as in vivo molecular imaging agents using the ${ }^{19} \mathrm{~F}$ magnetic resonance imaging system, which is centered on the $\mathrm{CF}_{3}$ resonance principle. The covalent attachment of perfluoroalkyl substituents $\left(-\mathrm{NHCOCF}_{2}-\mathrm{CF}_{2}-\mathrm{CF}_{3}\right)$ to the surface of G3 PAMAM dendrimers mediated self-assembly (specific formation) into a complex system with unique and adjustable physiochemical properties related to the $\mathrm{pH}$ of the external environment ( $\mathrm{pH} \mathrm{2,7}$ and 12). Electrostatic repulsive forces were responsible for driving particulate disassembly of the perfluorinated G3 PAMAM-dendrimers. $\mathrm{pH}$-dependent $\mathrm{T} 1$ relaxation times
(298.3, 410.7, and $428.8 \mathrm{~ms}$ at $\mathrm{pH} \mathrm{7,5}$, and 2, respectively) were observed by ${ }^{19} \mathrm{~F}$ magnetic spectroscopy, showing a stable and rigid network at approximately $\mathrm{pH} 7$, but was disrupted at $\mathrm{pH}$ 2. This disassembly occurred over time and could allow a potential control of the release of encapsulated agents. Then, a generation 6 fluorinated dendrimer was prepared and PEG chains were grafted on its surface to enhance its circulation and transport properties in the blood. This PEGylated nanoparticles have been used in in vivo experiments, and was injected intravenously into the female B6 mouse systemic circulation. ${ }^{19} \mathrm{~F}$ and ${ }^{1} \mathrm{H}$ images showed the presence of the PEGylated nanoparticles in the mouse kidney vasculature.

Recently, Luong et al. [45] highlighted the synthesis and development of polyvalent theranostic nanocarriers. The construction of this nanoparticle is based on the superparamagnetic iron oxide nanoparticle core $\left(\mathrm{Fe}_{3} \mathrm{O}_{4}\right)$ decorated with a FA-G4 PAMAM dendrimer surface that encapsulates the highly potent hydrophobic anticancer agent 3,4-difluorobenzylidene-curcumin. The 3-aminopropyl trimethoxysilane chain links the FA-dendrimer and the $\mathrm{Fe}_{3} \mathrm{O}_{4}$ particle (Fig. 11). Compared with nontargeted nanoparticles, the targeted nanoparticles exhibited an improved ability to enhance MRI contrast and faster cellular uptake in both SKOV3 ovarian and HeLa cervical cancer cells. These tumor cells overexpress FA receptors on the tumor surface. In addition, the targeted nanoparticles resulted in a higher percentage of apoptotic and necrotic cells with the ability to upregulate phosphatase and tensin homologue deleted on chromosome ten (PTEN) and caspase-3, and downregulate nuclear factor- $\kappa \mathrm{B}(\mathrm{NF}-\kappa \mathrm{B})$. This anticancer profile could help to overcome anticancer drug resistance and the recurrence of cancer after initial treatment. 


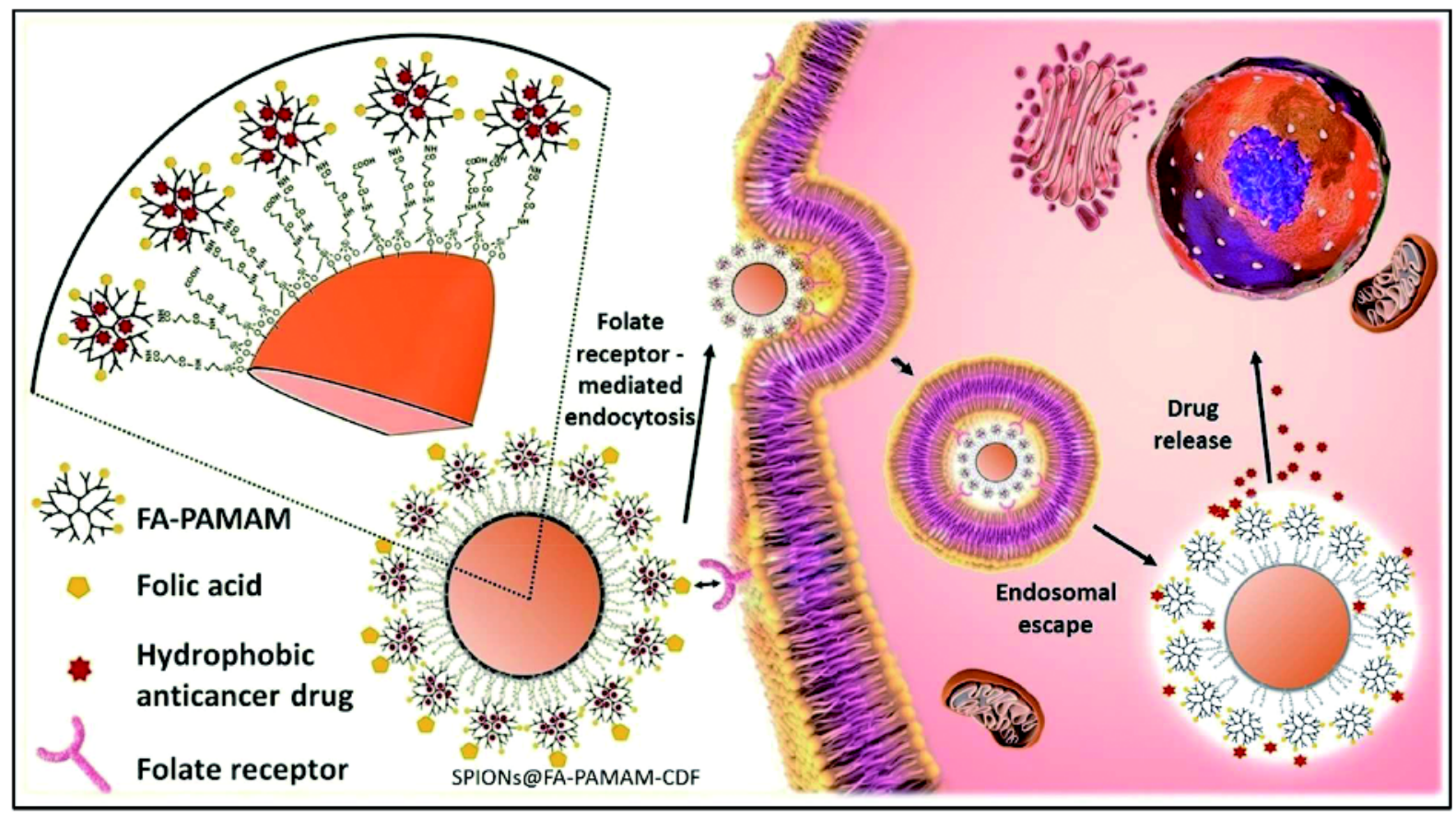

Figure 11 Pictorial representation of the folate receptor-mediated endocytosis followed by drug release of the targeted theranostic formulation SPIONs@FA-PAMAM-CDF in cancer cells overexpressing folate receptors. Reprinted with permission from [45]. Copyright 2018, American Chemical Society.

\section{Gamma scintigraphy}

Almutairi et al. [46] have developed a biodegradable and noninvasive ${ }^{76} \mathrm{Br}$ (radiohalogen moiety)-labeled positronemitting dendritic nanoprobe targeting $\alpha_{v} \beta_{3}$ integrin receptors in an angiogenic mouse model. As shown in Fig. 12 , the architecture of this PET dendritic nanoprobe is based on a modular multivalent core-shell scaffold consisting of a biodegradable heterofunctional dendritic core functionalized with heterobifunctional polyethylene oxide (PEO) chains to protect the shell. The PEO chains dictate PKs and maintain the biological activity. In addition, the radioactive moieties have been introduced in several branches of the dendritic core to prevent in vivo dehalogenation, whereas cyclic arginine-glycine-aspartic acid (RDG) moieties were introduced at the terminal ends of the PEO chains, enhancing their accessibility to $\alpha_{v} \beta_{3}$ integrin receptors. This targeted nanoprobe displayed a 50fold enhanced binding affinity to $\alpha_{v} \beta_{3}$ integrin receptors compared with the monovalent RGD peptide alone, with $\mathrm{IC}_{50 \text { s }}$ of approximately 0.18 and $10.5 \mathrm{nmol} \mathrm{L}^{-1}$, respectively. Based on cell uptake assays in $\alpha_{v} \beta_{3}$-positive M21 melanoma cells compared with $\alpha_{v} \beta_{3}$-negative M21 melanoma cells, the targeted nanoprobe (RGD-targeting moieties) showed a six-fold improvement in $\alpha_{v} \beta_{3}$ receptor-mediated endocytosis $\left(\alpha_{v} \beta_{3}\right.$-positive M21 mela-

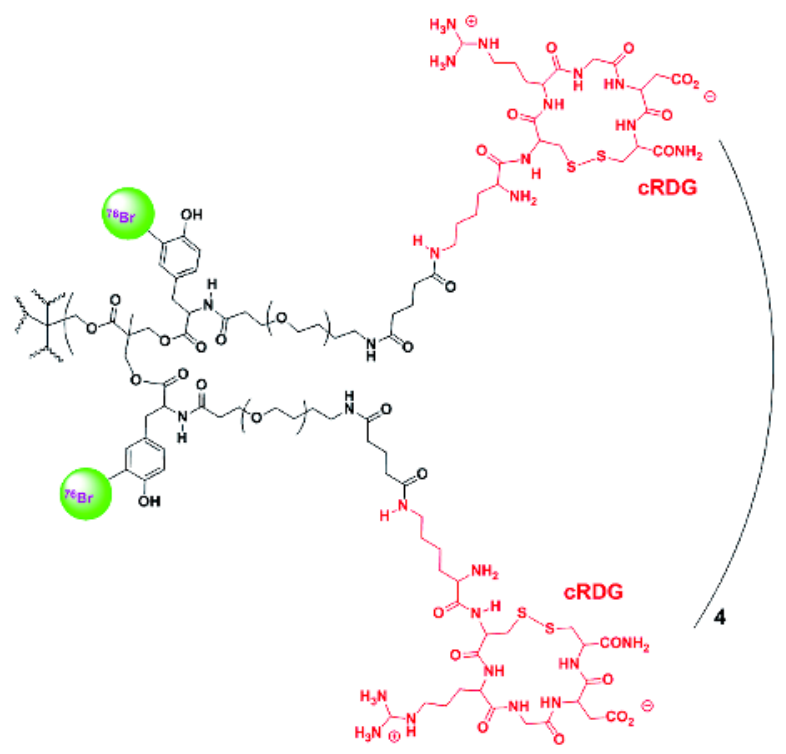

Figure 12 Chemical structure of PET ${ }^{76} \mathrm{Br}$-cRGD nanoprobe targeting $\alpha_{v} \beta_{3}$-integrin. Modified from Ref. [46]. Copyright 2009, The National Academy of Sciences of the USA.

noma cells) compared with the non-targeted nanoprobe. No enhancement was observed in $\alpha_{v} \beta_{3}$-negative M21 melanoma cells. In in vivo studies in a hindlimb ischemia 


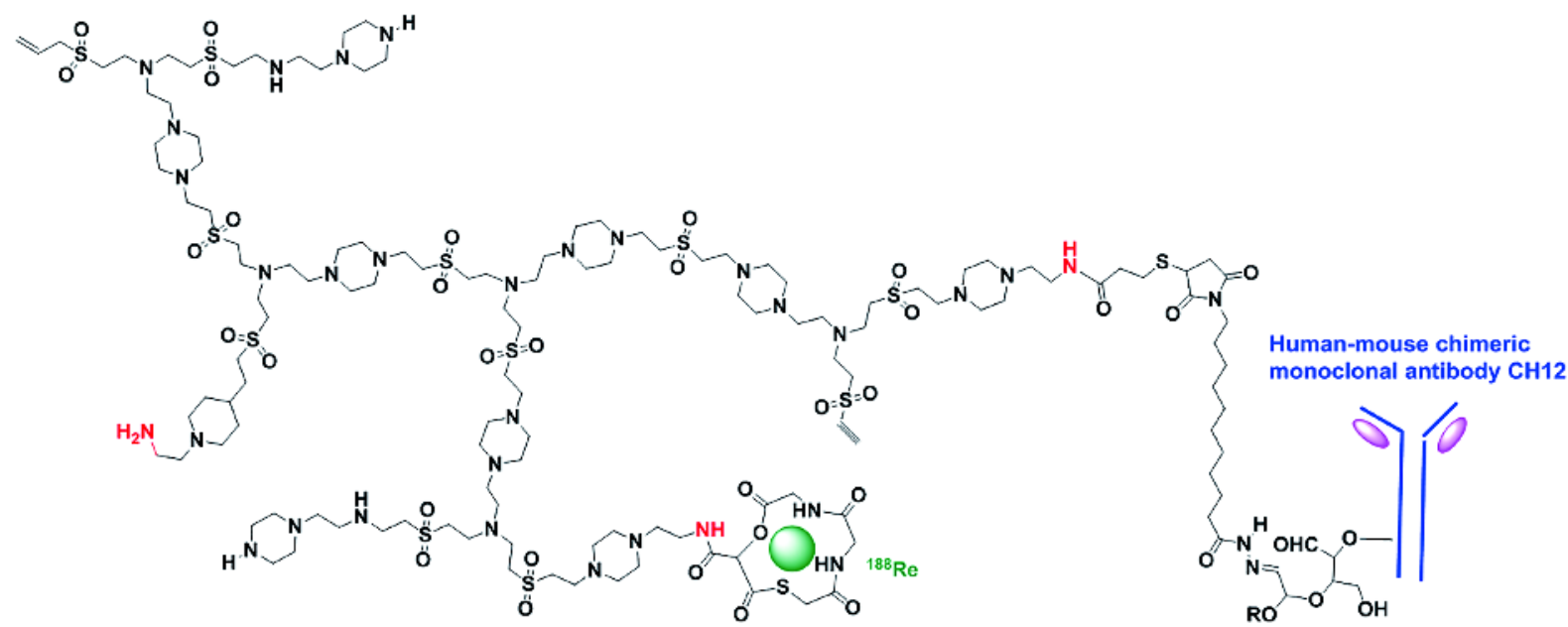

Figure 13 Schematic structure of CH12-HSPA- ${ }^{188}$ Re. The links between the Ab and the chelate with the hyper branched polysulfonamine-based dendrimers are arbitrarily attributed.

model of rat angiogenesis with intravenous administration, high specific accumulation of the $76 \mathrm{Br}$-labeled dendritic nanoprobe targeting $\alpha_{v} \beta_{3}$-integrins was observed in angiogenic muscles, whereas the excretion profile showed fast urinary elimination of the non-targeted dendritic nanoprobe compared with the RGD-nanoprobe, also eliminated via the stomach and feces.

Similarly, Dijkgraaf et al. [47] synthesized DOTAconjugated multivalent cyclic-RGD dendrimers specifically targeting $\alpha_{v} \beta_{3}$ integrins in in vitro and in vivo (nude mice) models of SK-RC-52 tumors. The ${ }^{111}$ In-labeled RGD-dendrimers showed specific enhanced uptake in $\alpha_{v} \beta_{3}$ integrin-expressing tumors in vivo.

Kobayashi et al. [48] described the synthesis and development of the G4-PAMAM dendrimer (64 surface amines), which was conjugated with 43 molecules of 2-(pisothiocyanatobenzyl)-6-methyl-diethylene triamine penta-acetic acid (1B4M) and the murine monoclonal IgG1 (OST7) followed by the conjugation of ${ }^{111} \mathrm{In}$ or ${ }^{153} \mathrm{Gd}$ as labeling moieties to generate ${ }^{111}$ In-OST7-G4-(1B4M) 43 and ${ }^{153} \mathrm{Gd}-O S T 7-G 4-(1 \mathrm{~B} 4 \mathrm{M}) 43$ nanoparticles, respectively. The immunoreactivity, biodistribution, and tumor targeting of these two G4-PAMAM dendrimer derivatives were evaluated in mice. The maximum specific activity of ${ }^{111}$ In-OST7-G4-(1B4M) 43 and ${ }^{111}$ In-OST7-1B4M was 12,700 and $263 \mathrm{mCi} \mathrm{mg}^{-1}$, respectively. The binding efficiency to human osteosarcoma cells (KT005), which express the antigen of OST7 using OST7-G4-(1B4M)43 and OST7-1B4M was 91 and $84 \%$, respectively. Biodistribution studies in mice showed that ${ }^{111}$ In-OST7-G4$(1 \mathrm{~B} 4 \mathrm{M}) 43$ and ${ }^{153} \mathrm{Gd}-\mathrm{OST} 7-\mathrm{G} 4-(1 \mathrm{~B} 4 \mathrm{M}) 43$ were cleared faster from the blood and accumulated in the liver faster compared with ${ }^{111}$ In-OST7-1B4M and ${ }^{153}$ Gd-OST71B4M. ${ }^{153} \mathrm{Gd}-\mathrm{OST} 7-\mathrm{G} 4-(1 \mathrm{~B} 4 \mathrm{M}) 43$ displayed specific accumulation in the KT005 tumor site.

The same team evaluated the in vivo biodistribution of the G2-PAMAM dendrimer (16 surface amine groups) conjugated with $1 \mathrm{~B} 4 \mathrm{M}$ and humanized anti-Tac IgG (HuTac) to generate the G2-PAMAM-IB4M-HuTac dendrimer, which was then radiolabeled with ${ }^{111}$ In and ${ }^{88} \mathrm{Y}$ [49]. The maximum specific activity was $\sim 1.2 \mathrm{mCi}$ $\mathrm{mg}^{-1}$ with ${ }^{111} \mathrm{In}$, and $\sim 0.1 \mathrm{mCi} \mathrm{mg}^{-1}$ with ${ }^{88} \mathrm{Y}$. Significantly, ${ }^{111}$ In-G2-PAMAM-IB4M-HuTac and ${ }^{88}$ Y-G2-PAMAMIB4M-HuTac accumulated in the liver, kidney, spleen, and bone in nude mice following intravenous administration. Radiolabeled G2-PAMAM-1B4M-HuTac dendritic nanoprobes showed faster blood clearance and greater liver and spleen accumulation compared with native HuTac.

Li and coworkers [50] developed the ${ }^{188}$ Re-labeled hyperbranched polysulfonamine-based dendrimers (HPSA), named CH12-HSPA- ${ }^{188} \mathrm{Re}$, as a robust tool for targeted cancer diagnosis and radiotherapy system to perform SPECT imaging studies (Fig. 13). HPSA is an interesting biomaterial due to its strong intracellular permeability. Two terminal amine groups were grafted onto the surface of HPSA: $N$-hydroxysuccinimidyl S-acetylmercaptoacetyl triglycinate (NHS-MAG3) for labeling ${ }^{188} \mathrm{Re}$, which is a versatile radioactive nuclide for both nuclear and radioimmunotherapy, and $N$-(k-maleimidoundecanoic acid) hydrazide for tethering the human-mouse chimeric monoclonal antibody $\mathrm{CH} 12$, which selectively recognizes epidermal growth factor receptor vIII (EGFRvIII). EGFR is a cell-surface receptor overexpressed in the neovascu- 
lature of many tumor types.

This theranostic system $\left({ }^{188} \mathrm{Re}-\mathrm{CH} 12\right.$-HSPA $)$ showed relevant in vitro stability against the competitive agent cysteine, and specifically targeted EGFRvIII-positive human hepatocarcinoma cells (EGFRRvIII-overexpressed Huh7 EGFRRvIII cells) in vitro, and in vivo in $\mathrm{Hu}$ h7EGFRvIII tumor cell-burdened BALB/c mice following intravenous administration. With SPECT imaging, the circulation time of ${ }^{188} \mathrm{Re}-\mathrm{CH} 12-\mathrm{HSPA}$ was prolonged compared with free ${ }^{188} \mathrm{Re}$ following tail vein injection. Based on the same in vivo experiment, the level of tumor radioactivity increased with time, while those of the kidney and blood were gradually decreased.

In a recent study, Shi and coworkers [51] used amineterminated G5 PAMAM dendrimers $\left(\mathrm{G} 5 \cdot \mathrm{NH}_{2}\right)$ as a platform to sequentially modify with 3 -(4'-hydroxyphenyl) propionic acid-OSu (HPAO) and FA linked with PEG, followed by acetylation modification of the dendrimer remaining surface amines and labeling of radioactive iodine-131 $\left({ }^{131} \mathrm{I}\right)$. Their data show that prior to ${ }^{131}$ I labeling, the generated G5.NHAc-HPAO-PEG-FA dendrimers conjugated with approximately 9.4 HPAO moieties per dendrimer are noncytotoxic at a concentration up to $20 \mu \mathrm{mol} \mathrm{L} \mathrm{L}^{-1}$, and can target cancer cells overexpressing FA receptors (FAR) due to the modified FA ligands. In the presence of the HPAO phenol group, radioactive ${ }^{131} \mathrm{I}$ is able to be efficiently labeled onto the dendrimer platform with good stability and high radiochemical purity. The developed dendrimeric nanoplatform enables targeted SPECT imaging and radiotherapy of a FAR-overexpressing xenografted tumor model in vivo.

In another study reported by Shi and coworkers [52], the G5 PAMAM dendrimers were sequentially linked with PEG, targeting agent chlorotoxin (CTX), and HPAO. This was followed by acetylation of the remaining dendrimer terminal amines and radiolabeling with ${ }^{131} \mathrm{I}$ to form the targeted theranostic dendrimeric nanoplatform. Results reveal that the dendrimer platform possessing 7.7 CTX and 21.1 HPAO moieties on each dendrimer displays excellent cytocompatibility in a given concentration range $\left(0-20 \mu \mathrm{mol} \mathrm{L}^{-1}\right)$ and can specifically target cancer cells overexpressing matrix metallopeptidase 2 (MMP2) due to the attached CTX. With the good stability and high radiochemical purity of the labeling of radioactive ${ }^{131} \mathrm{I}$, the dendrimer platform is able to be used for targeted SPECT imaging and radiotherapy of an MMP2-overexpressing glioma model in vivo.

Grünwald et al. [53] developed G5 PAMAM dendrimer-coated adenovirus (Ad5-CMV/NIS) encoding

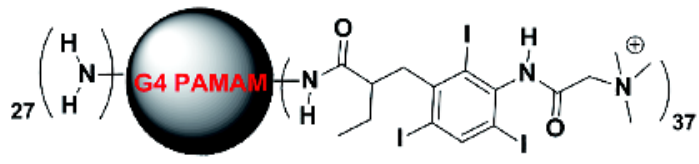

Figure 14 Schematic chemical structure of G4-PAMAM (DMAAIPA) $)_{37}$.

sodium iodide symporter as a theranostic gene nanoplatform using the ${ }^{123}$ I scintigraphy technique. The authors of this study highlighted the efficient therapeutic potential for systemic radiovirotherapy in a HUH7 liver cancer xenograft mouse model

\section{Computed tomography}

Yordanov and coworkers [54] prepared a water-soluble iodinated G4-PAMAM conjugated with $373-N-\left[\left(N^{\prime}, N^{\prime}-\right.\right.$ dimethylaminoacetyl)amino]-R-ethyl-2,4,6-triiodobenzenepropanoic acid (DMAA-IPA) molecules covalently linked by an amide bond with the surface of a dendrimer. The nanoparticles named G4-PAMAM (DMAA-IPA)37 bear 111 iodine atoms per dendrimer (Fig. 14). Importantly, the DMAA-IPA nanoparticles were specifically designed to improve solubility by introducing positive charges (ammonium salts), which did not affect the stability of the link between the DMAA-IPA and the dendrimer. These nanoparticles has an average molecular weight of $37,000 \mathrm{~g} \mathrm{~mol}^{-1}$, a hydrodynamic radius of $2.4 \mathrm{~nm}$, and an iodine content of $\sim 33 \%$. G4-PAMAM $(\text { DMAA-IPA })_{37}$ represents a first-in-class dendritic nanoparticle for CT imaging due to its high iodine loading capacity.

${ }^{177}$ Lu-G4-PAMAM dendrimer-folate-bombesin with gold nanoparticles in dendritic cavities has been synthesized by Mendoza-Nava et al. (Fig. 15) [55]. This nanoparticle, named ${ }^{177} \mathrm{Lu}$-DenAuNP-folate-bombesin, represents a potential theranostic radiopharmaceutical agent. Bombesin, a 14-amino acid peptide, and bombesin receptors, have been demonstrated to play a role in cancer. Gastrin-releasing peptide receptor is a bombesin receptor subtype frequently expressed in tumors. Binding studies in the T47D breast tumor cell line, which overexpresses FRs and gastrin-releasing peptide receptors, showed specific cell uptake of these nanoparticles. After intratumoral administration, high retention in T47D-induced tumors in mice was observed, and ${ }^{177} \mathrm{Lu}-\mathrm{G} 4-\mathrm{PA}-$ MAM dendrimer-folate-bombesin remained in the T47D tumor up to $96 \mathrm{~h}$.

Due to the higher X-ray attenuation coefficient of $\mathrm{Au}$ nanoparticles than that of iodine for iodine-based CT contrast agents (e.g., Omnipaque), Au nanoparticles have 


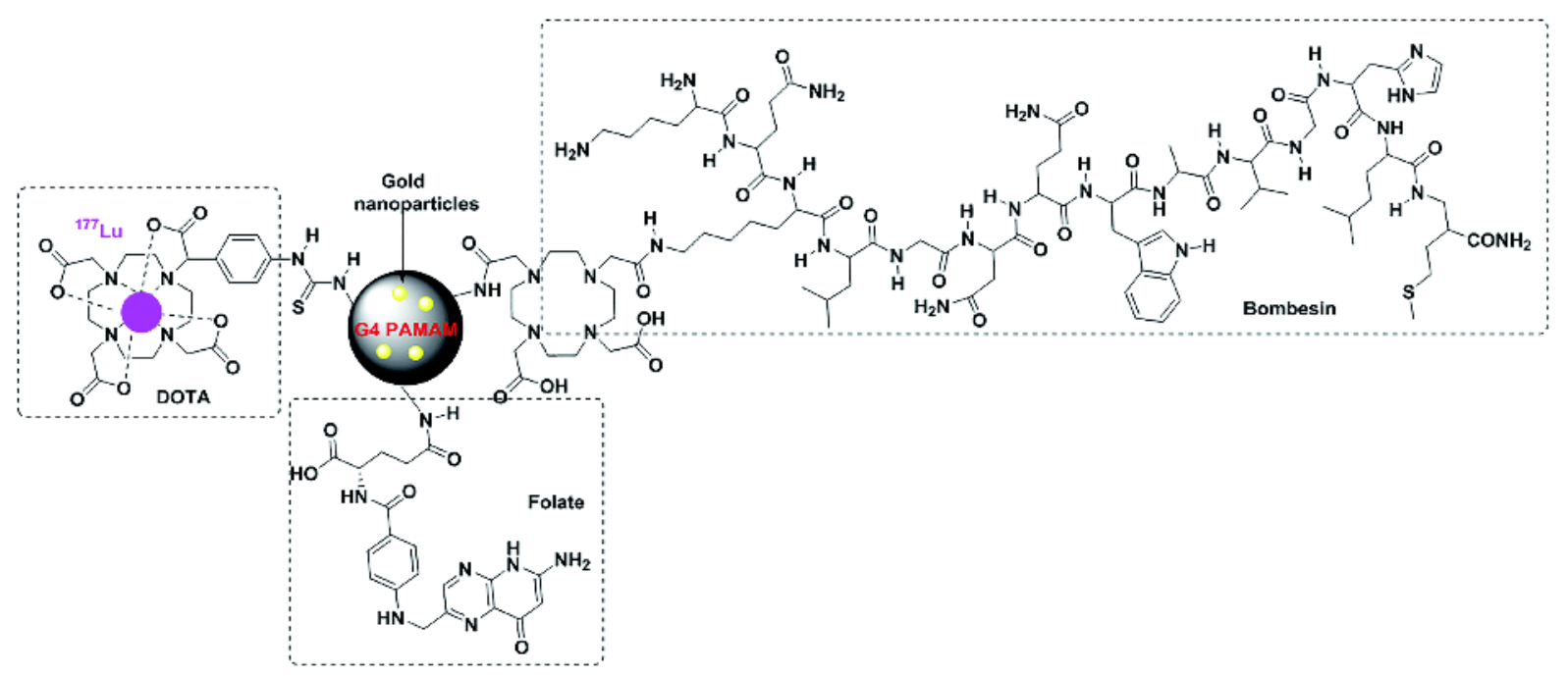

Figure 15 Schematic chemical structure of ${ }^{177} \mathrm{Lu}$-DenAuNP-folate-bombesin.

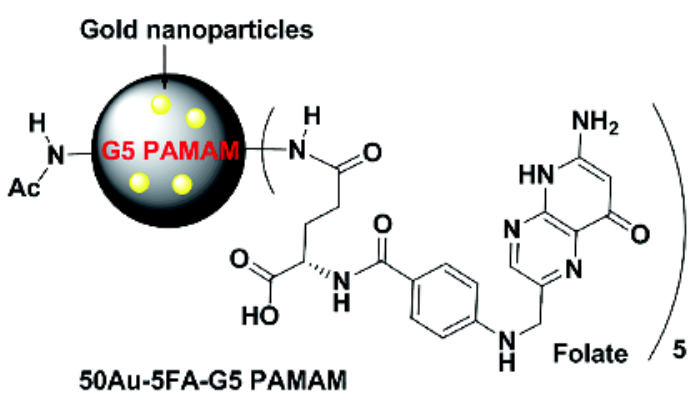

Figure 16 Schematic chemical structure of 50Au-5FA-G5 PAMAM.

been entrapped within dendrimers for various CT imaging applications [56-58]. In order to reduce the dendrimer terminal amine-induced cytotoxicity, the dendrimer terminal amines can be acetylated, and the acetylated dendrimer-entrapped gold nanoparticles (AuDENPs) can be used for blood pool [59] and tumor [60] CT imaging.

In a typical work, Wang and coworkers [60] from Shi's team reported the development of acetylated G5 PAMAM Au-DENPs for in vitro and in vivo CT imaging of cancer cells. These nanoparticles have been used for both in vitro and in vivo CT imaging of a SPC-A1 human lung adenocarcinoma cell line. Micro-CT images showed that SPC-A1 cells could be detected under X-ray after incubation in vitro, showing that the nanoparticles were uptaken in the lysosomes of SPC-A1 cells. In a mouse xenograft tumor model, after both intratumoral and intraperitoneal administration of the nanoparticles, high image resolution was observed. Interestingly, based on flow cytometric analysis of the cell cycle, no changes in cell morphology, viability, or the cell cycle were observed, indicating the biocompatibility of Au-DENPs nanoparticles.

In another study, Shi et al. [61] developed acetylated FA-G5 PAMAM dendrimer-entrapped gold nanoparticles that were suitable for in vitro and in vivo $\mathrm{CT}$ imaging of cancer cells, such as the human lung adenocarcinoma cell line (SPC-A1 cells; Fig. 16). Fifty Au per NAc-G5 PAMAM dendrimers and five FA units per dendrimer have been conjugated (named 50Au-5FA-G5 PAMAM). Gold nanoparticles have been used as probes in optical molecular imaging for cancer detection and treatment due to their surface plasmon absorption and light-scattering properties [62,63]. In addition, gold offers several advantages over conventional iodine-based agents, such as higher X-ray absorption coefficient and no specific toxicity, as well as tunable surface modifications for introduction of the targeting ligand [64]

Micro-CT images have shown that SPC-A1 cells could be detected under X-ray after incubation with this acetylated Au-PAMAM dendrimer in vitro and in vivo. Thus, xenograft tumors in mice can be imaged after both intratumoral and intraperitoneal administration of these nanoparticles. The uptake process of this nanomaterial in SPC-A1 cells occurs in lysosomes, and has been demonstrated using transmission electron microscopy. After tumor cell incubation, no cell damage (e.g., morphology changes), as well as no changes in the cell cycle were demonstrated, indicating their low toxicity and good 


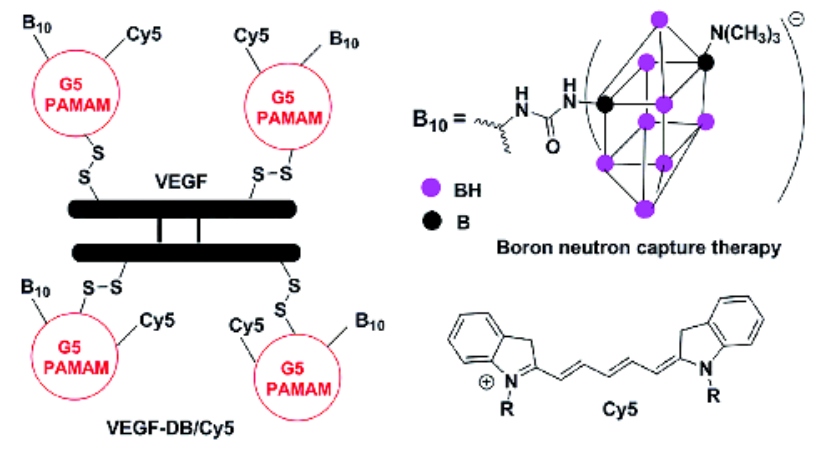

Figure 17 Schematic structure of VEGF-DB/Cy5.

biocompatibility.

In order to achieve higher loading of Au nanoparticles within the dendrimers, the dendrimer periphery can be modified with PEG [65]. Further, through the PEGylation chemistry, targeting ligands of folate [66] or lactobionic acid [67] can be linked onto the surface of Au-DENPs through the PEG spacer for targeted CT imaging of FRexpressing KB tumor and human hepatocellular carcinoma tumor, respectively. To avoid the use of expensive high generation PAMAM dendrimers, low-generation dendrimers (e.g., G2) can also be modified with PEG for effective entrapment of $\mathrm{Au}$ nanoparticles with a size of $1-2 \mathrm{~nm}$ for tumor CT imaging applications $[68,69]$. Alternatively, dendrimer-stabilized Au nanoparticles ( $\mathrm{Au}$ DSNPs) can be prepared using G2 PAMAM dendrimers as a stabilizer under a hydrothermal condition without additional reducing agents for animal organ [70] and tumor [71] CT imaging.

To further improve the $\mathrm{CT}$ imaging sensitivity, AuDENPs can be combined with diatrizoic acid (DTA), which is an iodine-based small molecular CT contrast agents. The Au-DENPs can be modified with DTA via EDC/NHS chemistry after the formation of Au nanoparticles to improve the CT imaging sensitivity due to the co-existence of two types of radiodense elements of $\mathrm{Au}$ and I [72]. Alternatively, DTA-modified G5 PAMAM dendrimers can be used as a template to synthesize AuDENPs. After the acetylation of dendrimer surface amines, Au DSNPs can be formed. The formed functional $\mathrm{Au}$ DSNPs can be used for enhanced blood pool CT imaging due to the presence of both elements of $\mathrm{Au}$ and I [73].

\section{Optical imaging}

Backer et al. [74] synthesized and developed vascular endothelial growth factor (VEGF)-BD/Cy5 nanoparticles for NIR tumor vasculature imaging (Fig. 17). Boronated
G5-PAMAM dendrimers (128 surface amino groups) were conjugated with 1) 1,050-1,100 decaborate-boron atom systems per dendrimer for NIR imaging and potential boron neutron capture therapy, 2) VEGF (4:1 molar ratio) to target tumor neovasculature, and 3) nearIR Cy5 dye allowing near-IR fluorescent imaging both in vitro and in vivo. This boronated dendrimer displayed no cytotoxicity against HEK293 cells expressing VEGFR-2. Based on NIR imaging studies, selective accumulation in $4 \mathrm{~T} 1$ mouse breast carcinoma was observed, mainly at the tumor periphery where angiogenesis was most active. Interestingly, this accumulation decreased in mice pretreated with VEGF-fusion toxin specifically killing VEGFR2-over expressing endothelial cells.

Tsien et al. [75] prepared dendrimers functionalized with fluorescently-labeled activatable cell-penetrating peptides, which are activated upon exposure to proteases characteristic of tumor tissues. These dendrimers were used to visually delineate the margin between tumor and adjacent tissues, during the resection surgery of mammary adenocarcinoma tumors in transgenic mice. These mice had better long-term tumor-free survival and overall survival than those treated by classical surgery without the help of the dendrimer.

Taratula et al. [76] described the preparation of G5 polypropylenimine (PPI) dendrimer-encapsulated silicon naphthalocyanine $(\mathrm{SiNc})$ as a nanoplatform for NIR fluorescence imaging and combinatorial anticancer phototherapy with dual photodynamic (PDT) and photothermal (PTT) therapeutic mechanisms. Encapsulation of SiNc occurs in the hydrophobic cavity of PPI dendrimers providing its aqueous solubility and its NIR fluorescence, PDT and PTT imaging properties. This construction showed high photostability of SiNc, and under NIR irradiation manifested robust heat generation capability $\left(\Delta T=40^{\circ} \mathrm{C}\right)$, producing reactive oxygen species (ROS) for PDT and PTT anticancer therapy. In addition, no SiNc release has been observed. Interestingly, by regulating the laser power density, the therapeutic mechanism of the SiNc-nanoprobe could be switched from PDT to combinatory PDT-PTT treatment. Importantly, in vivo, the SiNc-nanoprobe combined with NIR irradiation in nude mice completely eradicated A2780/AD resistant ovarian cancer cells transplanted into the animal.

The same team highlighted the synthesis and development, for PDT, of a multifunctional theranostic platform using silicon-based phtalocyanine moieties (imaging agents), which are encapsulated into G4 PPI dendrimers named PEG-G4 PPI-LHRH-PcSi $(\mathrm{OH})(\mathrm{mob})$ (Fig. 18) [77]. Phthalocyanines (Pc) have outstanding NIR optical 
properties and fluorescence emission but suffer in their tendency to form aggregates through $\pi-\pi$ staking and hydrophobic interactions in an aqueous medium. The theranostic properties of this platform are completed by the production of toxic ROS upon exposure to light to tackle tumor cells. To improve the biocompatibility of this nanoparticle, its surface has been modified with PEG chains. In addition, luteinising hormone-releasing hormone (LHRH) protein was also grafted on the PPI surface through the PEG chains for tumor cell selectivity. The use of both PEG chains and LHRH peptide decreased the cytotoxicity of this platform and enhanced internalization into cancer cells. Low dark cytotoxicity (cell viability), and strong phototherapeutic effects due to high production of intracellular ROS were observed in LHRH receptor-positive A280/AD multidrug-resistant human ovarian carcinoma cells compared with LHRH receptornegative SKOV-3 human ovarian carcinoma cell lines. No substantial difference was observed between cellular internalization of LHRH-targeted and non-targeted particles into LHRH-negative cancer cells. In vivo intravenous administration of tumor-LHRH targeted nanoparticles in mice bearing human ovarian carcinoma xenografts induced good fluorescent images in different organs, such as the tumor and liver, compared with the spleen, kidney, heart, and lung, indicating effective tumor targeting capability of the nanoparticles.

Cytochrome $c$ is an essential mediator of apoptosis when released from the mitochondria to the cytoplasm, e. g., in response to DNA damage, and is observed in many cancer cells including cancer stem cells. Interestingly, the delivery of cytochrome $c$ directly into the cytoplasm of cancer cells selectively initiates apoptosis in many cancer cells [78].

Santra et al. [79] synthesized a water-soluble hyperbranched polyhydroxyl dendrimer for theranostic properties. These nanoparticles carried hydrophilic protein cytochrome $c$ as a cellular apoptotic initiator, dialkylcarbocyanine dye, which is an NIR amphiphilic fluorescent dye, and FA as targeting moieties to target FR-positive cancer cells. The human lung carcinoma cell line A549 (FR-positive) and the breast carcinoma cell line MCF7 (FR-negative) were selected for this study. The intracellular release of cytochrome $c$ and apoptosis were observed with confocal microscopy. These folate-conjugated nanoparticles induced apoptosis in FR-positive lung carcinoma cells (A549), but not in MCF7 tumor cell lines (FR-negative), suggesting the specificity of the nanoparticles' cytotoxic potency.

Interestingly, dendrimers were also used as coating

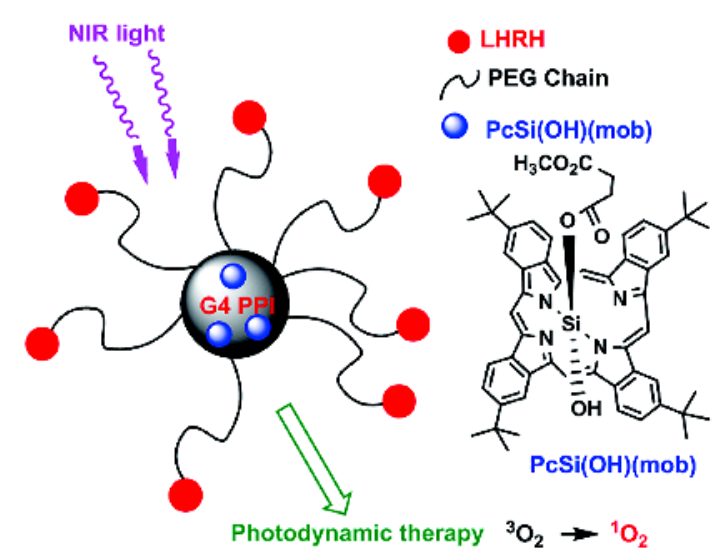

Figure 18 Schematic chemical structure of PEG-G4 PPI-LHRH-PcSi $(\mathrm{OH})(\mathrm{mob})$.

layers to encapsulate inorganic nanoparticles for molecular imaging. Thus, Zhao and coworkers [25] developed folate-PEG-3.5-PAMAM dendrimers encapsulating luminescent $\mathrm{CdSe} / \mathrm{ZnS}$ QDs as an imaging agent for selective targeting of FR-positive tumor cells. In this construction, 3.5 PAMAM dendrimers were used to encapsulate QDs. Based on in vivo experiments, the cellular uptake in HeLa tumor cells is more significant with folate-PEG-PAMAM dendrimers-QDs compared with nonfolate PAMAM dendrimer-QD systems. Folate-PEGPAMAM dendrimer-QDs are initially bound to tumor cell surfaces through FRs, followed by slow endosomal escape and release into tumor cells.

Phosphorus-containing dendrimers, synthesized in the group of Caminade and Majoral [80], have been functionalized with both fluorescent groups and bioactive terminal functions. The first generation phosphorhydrazone dendrimer functionalized by 12 azabisphosphonate groups is able to trigger the human immune system, and can induce the multiplication by several hundreds of the number of Natural Killer (NK) cells. NK cells are particularly important, as they are able to fight against various infection and numerous leukemia and carcinoma [81]. As shown by Poupot et al. [82] a fluorescently labeled analogue dendrimer (Fig. 19) was used to decipher the biological processes leading to the anticancer properties. It was shown that the first step is the anti-inflammatory activation of monocytes, which is particularly important against chronic inflammatory diseases $[83,84]$. In second time, a cross-talk between monocytes and NK cells induces the proliferation of the latter, including with blood from patients suffering of multiple myeloma disease [85].

Recently Mignani, Cresteil and Majoral et al. [86] de- 


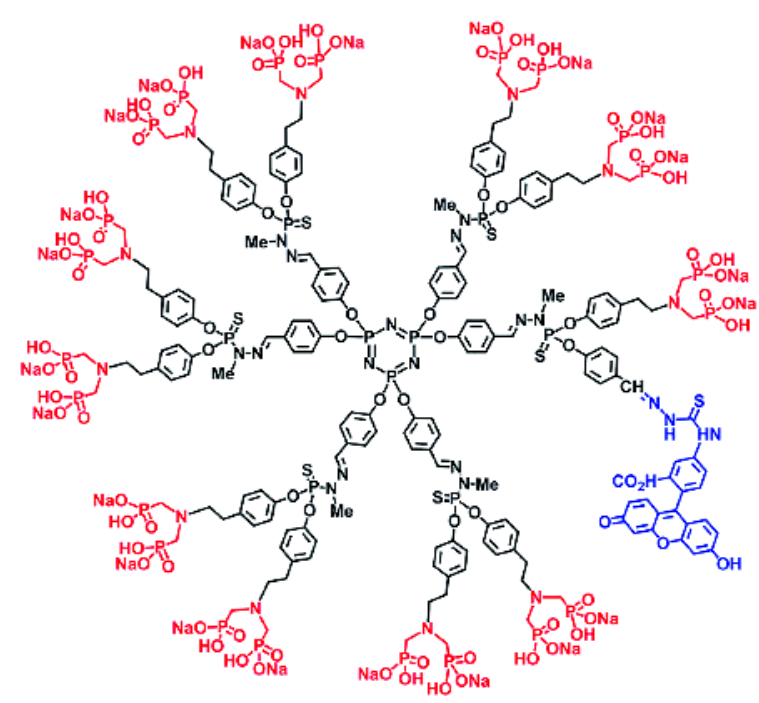

Figure 19 Fluorescently-labeled first generation phosphorhydrazone dendrimer able to trigger the human immune system towards either anti-inflammatory properties or anti-cancer properties.

scribed first-in-class phosphorhydrazone dendrimers which were capped with pyridine imine terminal functions (free or complexing $\mathrm{Cu}(\mathrm{II})$ ) showing good anticancer properties against a number of cancerous cell lines. The third generation was shown the most potent derivatives, with $\mathrm{IC}_{50 \mathrm{~s}}$ values ranging $0.3-1.6 \mu \mathrm{mol}$. Interestingly, the copper complexes were found more toxic toward cancerous cell lines a, but less toxic towards noncancer cell lines, than the free ligands. To get insight into their mode of action, a fluorescent analogue has been synthesized, in which the fluorophore are inside the structure (Fig. 20). It was shown that the free dendrimer and the corresponding copper complex behave differently inside the cells. The free dendrimer moderately activates caspase-3, whereas the complex strikingly reduces the caspase- 3 activity, and induces a noticeable translocation of Bax to the mitochondria, resulting in a severe DNA fragmentation. This is an original pathway for inducing apoptosis of cancer cells [87].

\section{Other examples of dendrimer-based theranostic nanosystems}

Dendrimers can also be modified onto other therapeutic inorganic nanoparticles such as gold nanostars (Au NSs) [88] and $\mathrm{MoS}_{2}$ nanoflakes [89] for combinational gene therapy and photothermal therapy. In particular, Au NSs modified with dendrimers can also be used for CT imaging. In their study, the authors report the synthesis of an Au NS-based theranostic platform stabilized with cyclic arginine-glycine-aspartic (Arg-Gly-Asp, RGD) peptidemodified amine-terminated generation 3 PAMAM dendrimers. The formed RGD-modified dendrimer-stabilized $\mathrm{Au}$ NSs (RGD-Au DSNSs) are used as a gene delivery vector to complex small interfering RNA (siR$\mathrm{NA}$ ) for CT imaging, thermal imaging, photothermal therapy, and gene therapy of tumors. The results show that the RGD-Au DSNSs are able to compact vascular endothelial growth factor siRNA and specifically deliver siRNA to cancer cells overexpressing $\alpha_{v} \beta_{3}$ integrin. Under NIR laser irradiation, the viability of cancer cells is only $20.2 \%$ after incubation with the RGD-Au DSNS/siRNA polyplexes, which is much lower than that of cells after single PTT or gene therapy treatment. Furthermore, in vivo results show that the RGD-Au DSNS/siRNA polyplexes enable tumor CT imaging, thermal imaging, photothermal therapy, and gene therapy after intratumoral injection.

\section{CONCLUSIONS AND PERSPECTIVES}

Nanoparticles such as dendrimers are significantly impacting the development of theranostic applications, which can be considered as the cement between diagnosis and treatment. Among the different nanoparticles used in theranostics, biodegradable and biocompatible dendrimers represent an attractive platform based on their high level of structural control, and potential for chemical functionalization.

Using dendrimers, a panel of diverse imaging modalities allowing diverse strategies to treat and visualize tumors can be developed: MRI, PET, SPECT, CT, and optical imaging. Recent approaches in theranostics using dendrimers were summarized in this review for biome-

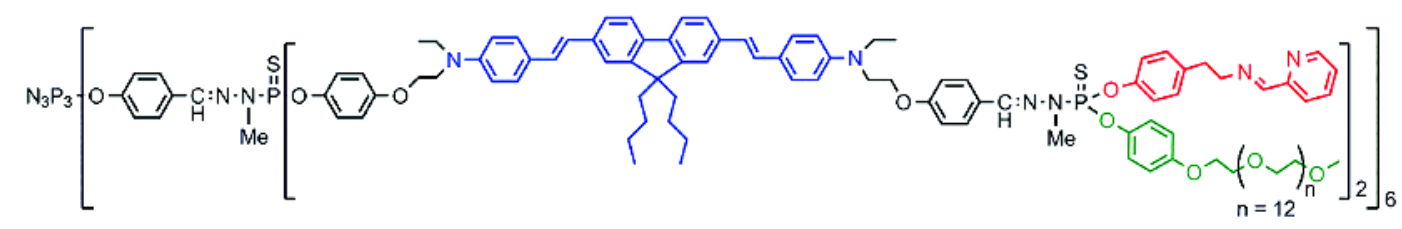

Figure 20 Phosphorhydrazone anti-cancer dendrimer having 12 fluorophore inside the structure, and 12 pyridine imine and PEG as terminal functions. 
Table 3 Imaging agents used with dendrimers

\begin{tabular}{cccc}
\hline MRI & PET & SPECT & CT \\
\hline $\mathrm{Gd}(\mathrm{III}),{ }^{19} \mathrm{~F}, \mathrm{Fe}_{2} \mathrm{O}_{3}$ & ${ }^{76} \mathrm{Br}$ & ${ }^{111} \mathrm{In},{ }^{88} \mathrm{Y},{ }^{153} \mathrm{Gd},{ }^{188} \mathrm{Re},{ }^{131} \mathrm{I}$ & $\begin{array}{c}\text { Boronated groups } \\
{ }^{111} \mathrm{In},{ }^{177} \text { Lu, gold }\end{array}$ \\
Diconnaphthalocyanine & $\begin{array}{c}\text { Dilicalcarbocyanine } \\
\text { QDs }\end{array}$ \\
\hline
\end{tabular}

dical applications in oncology. These strategies will help improve disease management. Table 3 notes the imaging agents used with dendrimers.

Using dendrimers as theranostic agents, several issues can be addressed, such as toxicity and biocompatibility, including long circulation time and clearance rate, as well as biodegradability and purification. In general, bench-tobedside translation of nanoparticles and dendrimers in particular, remains an important challenge. Indeed, to date, few dendrimers are in the clinical phase for systemic administration (vide supra), despite the fact that dendrimers are the focus of a large number of research publications, with approximately 2500 between 2006 and 2013 [90,91]. In addition, specifically regarding the use of dendrimers as MRI agents, McMahon and Bulte [14] have highlighted that over the last two decades, there has been an explosion of studies in MRI theranostics with over 400 papers published and 2800 citations a year (2013-2016).

The challenge is how to jump the 'valley of death' between academic researches based on an idea, general knowledge, basic research, and development processes and the clinical applications developed in pharmaceutical industries. Recently, several of us (Mignani, Shi, Rodrigues, Tomas and Majoral) have proposed a simple guideline to scientists (chemists, biologists, pharmacologists, engineers, and physicians) working in the dendrimer field based on several translational requirements to move towards an Investigational New Drug application (IND), which is an evaluation of the safety profile before initiating clinical trials [92]. In addition, Mignani and Majoral have defined the term dendrimer space concept as an approach that affords a new paradigm of thought for medicinal chemists and opens new and promising avenues for the identification of original and biocompatible dendrimers and dendrimer-based drugs [93], which have been analyzed by Leiro et al. [94] regarding the future of degradable dendrimers in theranostics.

Within the dendrimer field, in 2012, Starpharma Holding Limited (Melbourne, Australia) started two pivotal Phase III trials for the treatment of bacterial vaginosis with VivaGel $^{\circ}$ (SPL7013). In addition, Starpharma has now received FDA Phase III approval. Starpharma/ AstraZeneca has recently advanced from Phase I to Phase
II with poly(lysine)dendrimer based nanocarrier encapsulating docetaxel (DEP ${ }^{\circledR}$ docetaxel) showing superior anticancer activities against several important solid cancer types including breast, prostate, lung and ovarian tumors. Importantly, patients treated with DEP docetaxel had no neutropenia side effects, and lifethreatening toxicity seen in patients treated with conventional docetaxel formulations opening new opportunities to develop new anticancer agents in particular [8,9], and new therapeutic strategies in general.

Finally, the development of theranostic approach in other therapeutic domain such as HIV [95] and inflammation [96] should be possible. For instance, in the inflammation domain, the theranostic approach can be used to facilitate the evaluation of macrophage uptake and the biodistribution of the drug carrier [96].

Received 19 January 2018; accepted 6 March 2018; published online 8 April 2018

1 Ferrari M. Cancer nanotechnology: opportunities and challenges. Nat Rev Cancer, 2005, 5: 161-171

2 Torchilin VP. Recent advances with liposomes as pharmaceutical carriers. Nat Rev Drug Discov, 2005, 4: 145-160

3 Malam Y, Loizidou M, Seifalian AM. Liposomes and nanoparticles: nanosized vehicles for drug delivery in cancer. Trends Pharmacological Sci, 2009, 30: 592-599

4 Kakkar A, Traverso G, Farokhzad OC, et al. Evolution of macromolecular complexity in drug delivery systems. Nat Rev Chem, 2017, 1: 0063

5 Baig, T, Nayak J, Dwivedi V, et al. A review about dendrimers: Synthesis, types, characterization and applications. IJAPBC, 2015, 4: $44-59$

6 Astruc D, Boisselier E, Ornelas C. Dendrimers designed for functions: from physical, photophysical, and supramolecular properties to applications in sensing, catalysis, molecular electronics, photonics, and nanomedicine. Chem Rev, 2010, 110: 18571959

7 Vogtle F, Richard G, Werner N. Chapter 4. Types of dendrimers and their synthesis. In: Dendrimer Chemistry: Concepts, Syntheses, Properties, Applications, Wiley-VCH Verlag, 2009

8 Rupp R, Rosenthal, SL, Stanberry LR. VivaGel ${ }^{\text {TM }}$ (SPL7013 Gel): a candidate dendrimer-microbicide for the prevention of HIV and HSV infection. Int J Nanomedicine, 2007, 2: 561-566

9 Starpharma, Available at http://www.starpharma.com

10 Janib SM, Moses AS, MacKay JA. Imaging and drug delivery using theranostic nanoparticles. Adv Drug Deliver Rev, 2010, 62: 10521063 
11 Ma Y, Mou Q, Wang D, et al. Dendritic polymers for theranostics. Theranostics, 2016, 6: 930-947

12 Liu Y, Zhang N. Gadolinium loaded nanoparticles in theranostic magnetic resonance imaging. Biomaterials, 2012, 33: 5363-5375

13 Nottelet B, Darcos V, Coudane J. Aliphatic polyesters for medical imaging and theranostic applications. Eur J Pharm Biopharm, 2015, 97: 350-370

14 McMahon MT, Bulte JWM. Two decades of dendrimers as versatile MRI agents: a tale with and without metals. WIREs Nanomed Nanobiotechnol, 2017, 2: e1496

15 Dhar S, Liu Z, Thomale J, et al. Targeted single-wall carbon nanotube-mediated $\mathrm{Pt}(\mathrm{IV})$ prodrug delivery using folate as a homing device. J Am Chem Soc, 2008, 130: 11467-11476

16 Pike DB, Ghandehari H. HPMA copolymer-cyclic RGD conjugates for tumor targeting. Adv Drug Deliver Rev, 2010, 62: 167-183

17 Gao X, Luo Y, Wang Y, et al. Prostate stem cell antigen-targeted nanoparticles with dual functional properties: in vivo imaging and cancer chemotherapy. IJN, 2012, 7: 4037-4051

18 Talelli M, Rijcken CJF, van Nostrum CF, et al. Micelles based on HPMA copolymers. Adv Drug Deliver Rev, 2010, 62: 231-239

19 Christian DA, Cai S, Bowen DM, et al. Polymersome carriers: From self-assembly to siRNA and protein therapeutics. Eur J Pharm Biopharm, 2009, 71: 463-474

20 Shubayev VI, Pisanic Ii TR, Jin S. Magnetic nanoparticles for theragnostics. Adv Drug Deliver Rev, 2009, 61: 467-477

21 Gao Z, Kennedy AM, Christensen DA, et al. Drug-loaded nano/ microbubbles for combining ultrasonography and targeted chemotherapy. Ultrasonics, 2008, 48: 260-270

22 Thomas TP, Shukla R, Kotlyar A, et al. Dendrimer-based tumor cell targeting of fibroblast growth factor-1. Bioorg Medicinal Chem Lett, 2010, 20: 700-703

23 Ki Choi S, Thomas T, Li MH, et al. Light-controlled release of caged doxorubicin from folate receptor-targeting PAMAM dendrimer nanoconjugate. Chem Commun, 2010, 46: 2632-2634

24 Singh P, Gupta U, Asthana A, et al. Folate and Folate-PEG-PAMAM dendrimers: synthesis, characterization, and targeted anticancer drug delivery potential in tumor bearing mice. Bioconjugate Chem, 2008, 19: 2239-2252

25 Zhao Y, Liu S, Li Y, et al. Synthesis and grafting of folate-PEGPAMAM conjugates onto quantum dots for selective targeting of folate-receptor-positive tumor cells. J Colloid Interface Sci, 2010, 350: $44-50$

26 Li Y, Li Y, Zhang X, et al. Supramolecular PEGylated dendritic systems as $\mathrm{pH} /$ redox dual-responsive theranostic nanoplatforms for platinum drug delivery and NIR imaging. Theranostics, 2016, 6: 1293-1305

27 Wiener E, Brechbiel MW, Brothers $\mathrm{H}$, et al. Dendrimer-based metal chelates: A new class of magnetic resonance imaging contrast agents. Magn Reson Med, 1994, 31: 1-8

28 Zhu J, Gale EM, Atanasova I, et al. Hexameric $\mathrm{Mn}^{\mathrm{II}}$ dendrimer as MRI contrast agent. Chem Eur J, 2014, 20: 14507-14513

29 Aime S, Caravan P. Biodistribution of gadolinium-based contrast agents, including gadolinium deposition. J Magn Reson Imag, 2009, 30: 1259-1267

30 Kanal E, Tweedle MF. Residual or retained gadolinium: practical implications for radiologists and our patients. Radiology, 2015, 275: 630-634

31 Aime S, Barge A, Delli Castelli D, et al. Paramagnetic Lanthanide (III) complexes as $\mathrm{pH}$-sensitive chemical exchange saturation transfer (CEST) contrast agents for MRI applications. Magn Reson
Med, 2002, 47: 639-648

32 Zhang S, Winter P, Wu K, et al. A novel europium(III)-based MRI contrast agent. J Am Chem Soc, 2001, 123: 1517-1518

33 Ruiz-Cabello J, Barnett BP, Bottomley PA, et al. Fluorine $\left({ }^{19} \mathrm{~F}\right)$ MRS and MRI in biomedicine. NMR Biomed, 2011, 24: 114-129

$34 \mathrm{Xu} \mathrm{R}$, Wang $\mathrm{Y}$, Wang $\mathrm{X}$, et al. In vivo evaluation of a PAMAMcystamine-(Gd-DO3A) conjugate as a biodegradable macromolecular MRI contrast agent. Exp Biol Med (Maywood), 2007, 232: 1081-1089

35 Klemm PJ, Floyd Iii WC, Smiles DE, et al. Improving T1 and T2 magnetic resonance imaging contrast agents through the conjugation of an esteramide dendrimer to high-water-coordination Gd(III) hydroxypyridinone complexes. Contrast Media Mol Imag, 2012, 7: 95-99

36 Ye M, Qian Y, Shen Y, et al. Facile synthesis and in vivo evaluation of biodegradable dendritic MRI contrast agents. J Mater Chem, 2012, 22: 14369-14377

37 Ye M, Qian Y, Tang J, et al. Targeted biodegradable dendritic MRI contrast agent for enhanced tumor imaging. J Control Release, 2013, 169: 239-245

38 Li T, Qian Y, Ye M, et al. Synthesis and properties of a biodegradable dendritic magnetic resonance imaging contrast agent. Chin J Chem, 2014, 32: 91-96

39 Konda SD, Aref M, Wang S, et al. Specific targeting of folatedendrimer MRI contrast agents to the high affinity folate receptor expressed in ovarian tumor xenografts. Magna, 2001, 12: 104-113

40 Mohs AM, Lu ZR. Gadolinium(III)-based blood-pool contrast agents for magnetic resonance imaging: status and clinical potential. Expert Opin Drug Deliver, 2007, 4: 149-164

41 Kaneshiro TL, Jeong EK, Morrell G, et al. Synthesis and evaluation of globular Gd-DOTA-monoamide conjugates with precisely controlled nanosizes for magnetic resonance angiography. Biomacromolecules, 2008, 9: 2742-2748

42 Cyran CC, Fu Y, Raatschen HJ, et al. New macromolecular polymeric MRI contrast agents for application in the differentiation of cancer from benign soft tissues. J Magn Reson Imag, 2008, 27: 581589

43 Filippi M, Catanzaro V, Patrucco D, et al. First in vivo MRI study on theranostic dendrimersomes. J Control Release, 2017, 248: 4552

44 Criscione JM, Le BL, Stern E, et al. Self-assembly of pH-responsive fluorinated dendrimer-based particulates for drug delivery and noninvasive imaging. Biomaterials, 2009, 30: 3946-3955

45 Luong D, Sau S, Kesharwani P, et al. Polyvalent folate-dendrimercoated iron oxide theranostic nanoparticles for simultaneous magnetic resonance imaging and precise cancer cell targeting. Biomacromolecules, 2017, 18: 1197-1209

46 Almutairi A, Rossin R, Shokeen M, et al. Biodegradable dendritic positron-emitting nanoprobes for the noninvasive imaging of angiogenesis. Proc Natl Acad Sci USA, 2009, 106: 685-690

47 Dijkgraaf I, Rijnders AY, Soede A, et al. Synthesis of DOTAconjugated multivalent cyclic-RGD peptide dendrimers via 1,3dipolar cycloaddition and their biological evaluation: implications for tumor targeting and tumor imaging purposes. Org Biomol Chem, 2007, 5: 935-944

48 Kobayashi H, Sato N, Saga T, et al. Monoclonal antibody-dendrimer conjugates enable radiolabeling of antibody with markedly high specific activity with minimal loss of immunoreactivity. Eur J Nucl Med, 2000, 27: 1334-1339

49 Kobayashi $\mathrm{H}, \mathrm{Wu} \mathrm{C}, \mathrm{Kim} \mathrm{MK}$, et al. Evaluation of the in vivo 
biodistribution of indium-111 and yttrium-88 labeled dendrimer1B4M-DTPA and its conjugation with anti-tac monoclonal antibody. Bioconjugate Chem, 1999, 10: 103-111

500 Li N, Jin Y, Xue LZ, et al. ${ }^{188}$ Re-Labeled hyperbranched polysulfonamine as a robust tool for targeted cancer diagnosis and radioimmunotherapy. Chin J Polym Sci, 2013, 3: 530-540

51 Zhu J, Zhao L, Cheng Y, et al. Radionuclide ${ }^{131} \mathrm{I}$-labeled multifunctional dendrimers for targeted SPECT imaging and radiotherapy of tumors. Nanoscale, 2015, 7: 18169-18178

52 Zhao L, Zhu J, Cheng Y, et al. Chlorotoxin-conjugated multifunctional dendrimers labeled with radionuclide ${ }^{131} \mathrm{I}$ for single photon emission computed tomography imaging and radiotherapy of gliomas. ACS Appl Mater Interfaces, 2015, 7: 19798-19808

53 Grünwald GK, Vetter A, Klutz K, et al. Systemic image-guided liver cancer radiovirotherapy using dendrimer-coated adenovirus encoding the sodium iodide symporter as theranostic gene. J Nucl Med, 2013, 54: 1450-1457

54 Yordanov AT, Lodder AL, Woller EK, et al. Novel iodinated dendritic nanoparticles for computed tomography (CT) imaging. Nano Lett, 2002, 2: 595-599

55 Mendoza-Nava H, Ferro-Flores G, Ramírez FM, et al. ${ }^{177} \mathrm{Lu}$-dendrimer conjugated to folate and bombesin with gold nanoparticles in the dendritic cavity: a potential theranostic radiopharmaceutical. J Nanomaterials, 2016, 2016: 1-11

56 Guo R, Shi X. Dendrimers in cancer therapeutics and diagnosis. CDM, 2012, 13: 1097-1109

57 Li D, Wen S, Shi X. Dendrimer-entrapped metal colloids as imaging agents. WIREs Nanomed Nanobiotechnol, 2015, 7: 678-690

58 Qiao Z, Shi X. Dendrimer-based molecular imaging contrast agents. Prog Polymer Sci, 2015, 44: 1-27

59 Peng C, Wang H, Guo R, et al. Acetylation of dendrimer-entrapped gold nanoparticles: Synthesis, stability, and X-ray attenuation properties. J Appl Polym Sci, 2011, 119: 1673-1682

60 Wang H, Zheng L, Peng C, et al. Computed tomography imaging of cancer cells using acetylated dendrimer-entrapped gold nanoparticles. Biomaterials, 2011, 32: 2979-2988

61 Wang H, Zheng L, Peng C, et al. Folic acid-modified dendrimerentrapped gold nanoparticles as nanoprobes for targeted CT imaging of human lung adencarcinoma. Biomaterials, 2013, 34: 470-480

62 Vinegoni C, Feruglio PF, Cortez-Retamozo V, et al. Imaging of molecular probe activity with Born-normalized fluorescence optical projection tomography. Opt Lett, 2010, 35: 1088-1090

63 Guo R, Li R, Li X, et al. Dual-functional alginic acid hybrid nanospheres for cell imaging and drug delivery. Small, 2009, 5: 709717

64 Connor EE, Mwamuka J, Gole A, et al. Gold nanoparticles are taken up by human cells but do not cause acute cytotoxicity. Small, 2005, 1: 325-327

65 Peng C, Zheng L, Chen Q, et al. PEGylated dendrimer-entrapped gold nanoparticles for in vivo blood pool and tumor imaging by computed tomography. Biomaterials, 2012y, 33: 1107-1119

66 Peng C, Qin J, Zhou B, et al. Targeted tumor CT imaging using folic acid-modified PEGylated dendrimer-entrapped gold nanoparticles. Polym Chem, 2013, 4: 4412-4424

67 Liu H, Wang H, Xu Y, et al. Lactobionic acid-modified dendrimerentrapped gold nanoparticles for targeted computed tomography imaging of human hepatocellular carcinoma. ACS Appl Mater Interfaces, 2014, 6: 6944-6953

68 Cao Y, He Y, Liu H, et al. Targeted CT imaging of human hepa- tocellular carcinoma using low-generation dendrimer-entrapped gold nanoparticles modified with lactobionic acid. J Mater Chem B, 2015, 3: 286-295

69 Liu $\mathrm{H}$, Wang $\mathrm{H}, \mathrm{Xu} \mathrm{Y}$, et al. Synthesis of PEGylated low generation dendrimer-entrapped gold nanoparticles for CT imaging applications. Nanoscale, 2014, 6: 4521-4526

70 Liu H, Xu Y, Wen S, et al. Facile hydrothermal synthesis of low generation dendrimer-stabilized gold nanoparticles for in vivo computed tomography imaging applications. Polym Chem, 2013, 4: $1788-1795$

71 Liu $\mathrm{H}, \mathrm{Xu} \mathrm{Y}$, Wen S, et al. Targeted tumor computed tomography imaging using low-generation dendrimer-stabilized gold nanoparticles. Chem Eur J, 2013, 19: 6409-6416

72 Guo R, Wang H, Peng C, et al. Enhanced X-ray attenuation property of dendrimer-entrapped gold nanoparticles complexed with diatrizoic acid. J Mater Chem, 2011, 21: 5120-5127

73 Peng C, Li K, Cao X, et al. Facile formation of dendrimer-stabilized gold nanoparticles modified with diatrizoic acid for enhanced computed tomography imaging applications. Nanoscale, 2012, 4: 6768-6778

74 Backer MV, Gaynutdinov TI, Patel V, et al. Vascular endothelial growth factor selectively targets boronated dendrimers to tumor vasculature. Mol Cancer Ther, 2005, 4: 1423-1429

75 Nguyen QT, Olson ES, Aguilera TA, et al. Surgery with molecular fluorescence imaging using activatable cell-penetrating peptides decreases residual cancer and improves survival. Proc Natl Acad Sci USA, 2010, 107: 4317-4322

76 Taratula O, Schumann C, Duong T, et al. Dendrimer-encapsulated naphthalocyanine as a single agent-based theranostic nanoplatform for near-infrared fluorescence imaging and combinatorial anticancer phototherapy. Nanoscale, 2015, 7: 3888-3902

77 Taratula O, Schumann C, Naleway MA, et al. A multifunctional theranostic platform based on phthalocyanine-loaded dendrimer for image-guided drug delivery and photodynamic therapy. Mol Pharm, 2013, 10: 3946-3958

78 Morales-Cruz M, Figueroa CM, González-Robles T, et al. Activation of caspase-dependent apoptosis by intracellular delivery of cytochrome c-based nanoparticles. J Nanobiotechnol, 2014, 12: 111

79 Santra S, Kaittanis C, Perez JM. Cytochrome $c$ encapsulating theranostic nanoparticles: a novel bifunctional system for targeted delivery of therapeutic membrane-impermeable proteins to tumors and imaging of cancer therapy. Mol Pharm, 2010, 7: 1209-1222

80 Caminade AM, Hameau A ̃̃, Majoral JP. Multicharged and/or water-soluble fluorescent dendrimers: properties and uses. Chem Eur J, 2009, 15: 9270-9285

81 Griffe L, Poupot M, Marchand P, et al. Multiplication of human natural killer cells by nanosized phosphonate-capped dendrimers. Angew Chem Int Ed, 2007, 46: 2523-2526

82 Poupot M, Griffe L, Marchand P, et al. Design of phosphorylated dendritic architectures to promote human monocyte activation. FASEB J, 2006, 20: 2339-2351

83 Hayder M, Poupot M, Baron M, et al. A phosphorus-based dendrimer targets inflammation and osteoclastogenesis in experimental arthritis. Sci Translational Med, 2011, 3: 81ra35-81ra35

84 Caminade AM, Fruchon S, Turrin CO, et al. The key role of the scaffold on the efficiency of dendrimer nanodrugs. Nat Commun, 2015, 6: 7722

85 Poupot M, Turrin CO, Caminade AM, et al. Poly(phosphorhydrazone) dendrimers: yin and yang of monocyte activation for 
human NK cell amplification applied to immunotherapy against multiple myeloma. NanoMed-Nanotechnol Biol Med, 2016, 12: 2321-2330

86

El Brahmi N, El Kazzouli S, Mignani SM, et al. Original multivalent copper(II)-conjugated phosphorus dendrimers and corresponding mononuclear copper(II) complexes with antitumoral activities. Mol Pharm, 2013, 10: 1459-1464

87 Mignani S, El Brahmi N, Eloy L, et al. Anticancer copper(II) phosphorus dendrimers are potent proapoptotic Bax activators. Eur J Medicinal Chem, 2017, 132: 142-156

88 Wei P, Chen J, Hu Y, et al. Dendrimer-stabilized gold nanostars as a multifunctional theranostic nanoplatform for CT imaging, photothermal therapy, and gene silencing of tumors. Adv Healthcare Mater, 2016, 5: 3203-3213

89 Kong L, Xing L, Zhou B, et al. Dendrimer-modified $\mathrm{MoS}_{2}$ nanoflakes as a platform for combinational gene silencing and photothermal therapy of tumors. ACS Appl Mater Interfaces, 2017, 9: 15995-16005

90 Vargas JG. Dendrimers: from the art of building precise molecules to the dissemination through the world. Braz J Pharm Sci, 2013, 49: 4-5

91 Kalhapure RS, Kathiravan MK, Akamanchi KG, et al. Dendrimers -from organic synthesis to pharmaceutical applications: an update. Pharmaceutical Dev Tech, 2015, 20: 22-40

92 Mignani S, Rodrigues J, Tomas H, et al. Bench-to-bedside translation of dendrimers: Reality or utopia? A concise analysis. Adv Drug Deliver Rev, 2017, 10.1016/j.addr.2017.11.007

93 Mignani S, Kazzouli SE, Bousmina M, et al. Dendrimer space concept for innovative nanomedicine: A futuristic vision for medicinal chemistry. Prog Polymer Sci, 2013, 38: 993-1008
94 Leiro V, Garcia JP, Tomás H, et al. The present and the future of degradable dendrimers and derivatives in theranostics. Bioconjugate Chem, 2015, 26: 1182-1197

95 Alberto RFR, Joao R, de Los Angeles MFM, et al. Principal physicochemical methods used to characterize dendrimer molecule complexes used as genetic therapy agents, nanovaccines or drug carriers. CPD, 2017, 23

96 Patel SK, Janjic JM. Macrophage targeted theranostics as personalized nanomedicine strategies for inflammatory diseases. Theranostics, 2015, 5: 150-172

Acknowledgements This review is the result of intense cooperation between France, China and Portugal in the domain of dendrimers and cannot be possible without the devotion of our coworkers, the work of the colleagues all over the world and the support of several funding agencies. Mignani S, Rodrigues J, and Tomas $\mathrm{H}$ acknowledge the support of FCT-Fundação para a Ciência e a Tecnologia (project PEst-OE/ QUI/UI0674/2013, CQM, Portuguese Government funds), and ARDITI through the project M1420-01-0145-FEDER-000005 - Centro de Química da Madeira - CQM+ (Madeira 14-20), and Majoral J-P also acknowledges the funds from Centre National de la Recherche Scientifique (CNRS, France). Shi X acknowledges the support by the National Natural Science Foundation of China (21773026 and 81761148028), and (Mignani S, Majoral J-P and Shi X) by the Sino-French Caiyuanpei Programme.

Author contributions Authors contributed equally.

Conflict of interest The authors declare that they have no conflict of interest. 

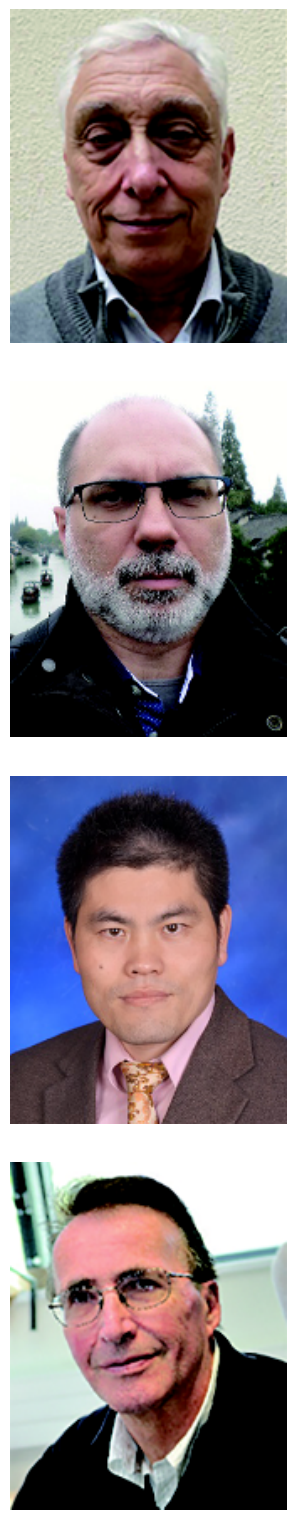

Serge Mignani was Head of the Medicinal Chemistry Department and Scientific Director (Sanofi). In 2017, he was nominated as Professor in medicinal chemistry at the Centro de Quimica da Madeira, University of Madeira at Fungal, Portugal. He is member of scientific advisory board of Glycovax Pharma (Montreal, Canada), and Sai Phytoceuticals (New Delhi, India). He is consultant in medicinal chemistry at the Indian Institute of Integrative Medicine (Prof. R. Vishwakarma, IIIM, Jammu, India), the 'Laboratoire Chimie de Coordination' (Prof. J-P. Majoral, Toulouse, France), and the Donghua University (Prof. X. Shi, Shanghai, China).

Joao Rodrigues is a staff member of the University of Madeira since 1999 (Portugal) and Adjunct Professor at Northwestern Polytechnical University, Xi'an (China) since June 2017. In September 2017, he was nominated member of the Scientific Board of the Portuguese National Science Foundation (FCT) in the areas of Exact Sciences and Engineering. In the last three years, he authored 24 papers and 2 book chapters (h index 21, i10 index $=30$ ). His main research interests are on the synthesis and characterization of molecular materials namely, nanoparticles, dendrimers and polymers for biomedical applications (e.g., emergent and infectious diseases, and oncology).
Xiangyang Shi obtained his PhD degree in 1998 from the Chinese Academy of Sciences. From 2002-2008, he was appointed as a research fellow, research associate II, research investigator, and research assistant professor in Michigan Nanotechnology Institute for Medicine and Biological Sciences, University of Michigan, Ann Arbor. In September 2008, he joined Donghua University as a full professor. He has published more than 268 peer-reviewed SCI-indexed journal articles. His current research interests are focused on dendrimer-based nanomedicine, and electrospun polymer nanofiber-based technology for applications in regenerative medicine, sensing, and therapeutics.

Jean-Pierre Majoral is Emeritus Director of Research, Exceptional Class at the CNRS in Toulouse. His research interest is focused on the design and the properties of macromolecules such as phosphorus dendrimers and hyperbranched polymers. Main efforts are directed at the use of dendrimers in medicinal chemistry, material sciences and catalysis. He is cofounder and scientific director of the start-up Dendris. He is a member of several Academies of Sciences worldwide, got a dozen of international awards, and is an author of over 635 publications, 7 books, 35 book chapters, and 45 patents (h index 65 , over 15,700 citations).

\section{树状大分子用于肿瘤诊疗原则的最新治疗应用}

Serge Mignani ${ }^{1,2^{*}}$, Joao Rodrigues ${ }^{2,3^{*}}$, Helena Tomas ${ }^{2}$, Anne-Marie Caminade ${ }^{4,5}$, Régis Laurent ${ }^{4,5}$, 史向阳 ${ }^{6 *}$, Jean-Pierre Majoral ${ }^{4,5^{*}}$

摘要 纳米粒子技术作为癌症诊断和治疗的交叉点, 极大地影响着抗肿瘤药物与肿瘤诊断剂的发展. 新型无创诊疗一体化纳米平台的发 展也因此得到了人们的广泛关注. 这些多功能的诊疗一体化平台包括：碳基纳米材料例如碳纳米管、药物缀合物、脂肪族聚合物、胶 束、囊泡、核-壳结构的纳米颗粒、微泡和负载不同造影剂和药物如肿瘤学领域中的化疗药物的树状大分子等. 树状大分子作为一类新 型高度可调控的超支化聚合物, 现已被开发出多种用于肿瘤诊疗一体化的纳米平台. 磁共振成像、 $\gamma$ 闪㷧扫描技术、计算机断层扫描和光 学成像等也成为通过树状大分子发展起来的核心技术用于肿瘤的诊疗. 不同的造影剂体系包括 $\mathrm{Gd}(\mathrm{III}) 、{ }^{19} \mathrm{~F} 、 \mathrm{Fe}_{2} \mathrm{O}_{3}(\mathrm{MRI}) 、{ }^{76} \mathrm{Br}(\mathrm{PET})$ 、 ${ }^{111} \mathrm{In} 、{ }^{88} \mathrm{Y} 、{ }^{153} \mathrm{Gd} 、{ }^{188} \mathrm{Re} 、{ }^{131} \mathrm{I}(\mathrm{SPECT}) 、{ }^{177} \mathrm{Lu}$ 、金纳米颗粒 $(\mathrm{CT})$ 和硼化基团、硅萫酞菁、二烷基羰花青和量子点光学成像染料等也已经 被开发使用. 